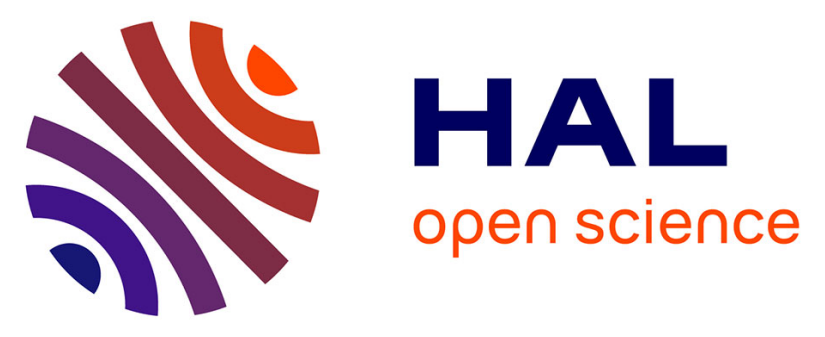

\title{
IDUA Mutational Profiling of a Cohort of 102 European Patients with Mucopolysaccharidosis type I: Identification and Characterization of 35 Novel alpha-L-iduronidase (IDUA) Alleles
}

Francesca Bertola, Mirella Filocamo, Giorgio Casati, Matthew Mort, Camillo Rosano, Anna Tylki-Szymańska, Beyhan Tuysuz, Orazio Gabrielli, Serena Grossi, Maurizio Scarpa, et al.

\section{- To cite this version:}

Francesca Bertola, Mirella Filocamo, Giorgio Casati, Matthew Mort, Camillo Rosano, et al.. IDUA Mutational Profiling of a Cohort of 102 European Patients with Mucopolysaccharidosis type I: Identification and Characterization of 35 Novel alpha-L-iduronidase (IDUA) Alleles. Human Mutation, 2011, 32 (6), 10.1002/humu.21479 . hal-00621299

\section{HAL Id: hal-00621299 \\ https://hal.science/hal-00621299}

Submitted on 10 Sep 2011

HAL is a multi-disciplinary open access archive for the deposit and dissemination of scientific research documents, whether they are published or not. The documents may come from teaching and research institutions in France or abroad, or from public or private research centers.
L'archive ouverte pluridisciplinaire $\mathbf{H A L}$, est destinée au dépôt et à la diffusion de documents scientifiques de niveau recherche, publiés ou non, émanant des établissements d'enseignement et de recherche français ou étrangers, des laboratoires publics ou privés. 


\section{Human Mutation}

WILEY

\section{IDUA Mutational Profiling of a Cohort of 102 European Patients with Mucopolysaccharidosis type I: Identification and Characterization of 35 Novel alpha-L-iduronidase (IDUA) Alleles}

\begin{tabular}{|c|c|}
\hline Journal: & Human Mutation \\
\hline Manuscript ID: & humu-2010-0583.R1 \\
\hline Wiley - Manuscript type: & Mutation in Brief \\
\hline $\begin{array}{r}\text { Date Submitted by the } \\
\text { Author: }\end{array}$ & 22-Jan-2011 \\
\hline Complete List of Authors: & $\begin{array}{l}\text { Bertola, Francesca; Milano Bicocca University, Consortium for } \\
\text { Human Molecular Genetics } \\
\text { Filocamo, Mirella; G.Gaslini, Laboratorio Diagnosi Pre-Postnatale } \\
\text { Malattie Metaboliche } \\
\text { Casati, Giorgio; Milano Bicocca University, Consortium for Human } \\
\text { Molecular Genetics } \\
\text { Mort, Matthew; Institute of Medical Genetics, School of Medicine, } \\
\text { Cardiff University } \\
\text { Rosano, Camillo; National Institute for Cancer Research (IST), } \\
\text { Bioinformatics and Structural Proteomics } \\
\text { Tylki-Szymańska, Anna; The Children's Memorial Health Institute, } \\
\text { Department of Metabolic Diseases } \\
\text { Tuysuz, Beyhan; Istanbul University Cerrahpasa, Pediatrics } \\
\text { Gabrielli, Orazio; Ospedali Riuniti, Presidio Salesi, Division of } \\
\text { Pediatrics } \\
\text { Grossi, Serena; IRCCS G. Gaslini, Laboratorio Diagnosi Pre- } \\
\text { Postnatale Malattie Metaboliche } \\
\text { Scarpa, Maurizio; University Children's Hospital, Department of } \\
\text { Pediatrics } \\
\text { Parenti, Giancarlo; Federico II University, Department of Pediatrics } \\
\text { Antuzzi, Daniela; Catholic University, Department of Pediatric } \\
\text { Sciences } \\
\text { Dalmau, Jaime; Hospital Infantil La Fe, Division of Metabolism, } \\
\text { Di Rocco, Maja; Istituto G. Gaslini, U.O. Pediatria II } \\
\text { Dionisi Vici, Carlo; Bambino Gesù Children's Hospital, Division of } \\
\text { Metabolism } \\
\text { Okur, Ilias; 13Department of Pediatric Nutrition and Metabolism, } \\
\text { Department of Pediatric Nutrition and Metabolism } \\
\text { Rosell, Jordi; Hospital Son Dureta, Genetics } \\
\text { Rovelli, Attilio; University of Milano Bicocca, San Gerardo Hospital, } \\
\text { Department of Pediatrics } \\
\text { Furlan, Francesca; University of Milano Bicocca, San Gerardo }\end{array}$ \\
\hline
\end{tabular}


Hospital, Department of Pediatrics

Rigoldi, Miriam; University of Milano Bicocca, San Gerardo Hospital, Department of Pediatrics

Biondi, Andrea; University of Milano Bicocca, San Gerardo Hospital, Department of Pediatrics

Cooper, David; Cardiff University, Institute of Medical Genetics, College of Medicine

Parini, Rossella; University of Milano Bicocca, San Gerardo Hospital, Department of Pediatrics

IDUA mutations, mucoplysaccharidosis type I, Hurler disease, Key Words: genotype-phenotype analysis, molecular modelling, MutPred analysis, in vitro splicing analysis

\section{SCHOLARONE ${ }^{\text {m }}$}

Manuscripts 


\section{IDUA Mutational Profiling of a Cohort of 102 European Patients with Mucopolysaccharidosis Type I: Identification and Characterization of 35 Novel $\alpha$-L-iduronidase (IDUA) Alleles}

OFFICIAL JOURNAL

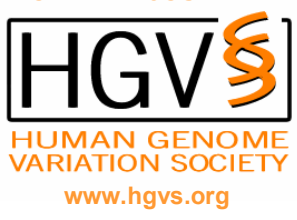

Francesca Bertola ${ }^{1 *}$, Mirella Filocamo ${ }^{2}$, Giorgio Casati ${ }^{1}$, Matthew Mort ${ }^{3}$, Camillo Rosano ${ }^{4}$, Anna Tylki-Szymanska ${ }^{5}$, Beyhan Tüysüz ${ }^{6}$, Orazio Gabrielli ${ }^{7}$, Serena Grossi ${ }^{2}$, Maurizio Scarpa ${ }^{8}$, Giancarlo Parenti ${ }^{9}, 10$, Daniela Antuzzi ${ }^{11}$, Jaime Dalmau ${ }^{12}$, Maja Di Rocco ${ }^{13}$, Carlo Dionisi Vici'14, llyas Okur ${ }^{15}$, Jordi Rosell16, Attilio Rovelli17, Francesca Furlan ${ }^{17}$, Miriam Rigoldi ${ }^{17}$, Andrea Biondi ${ }^{17}$, David N Cooper ${ }^{3}$, and Rossella Parini ${ }^{17}$

${ }^{1}$ Consortium for Human Molecular Genetics, Milano Bicocca University, Monza, Italy; ${ }^{2}$ S. S.D. Lab. Diagnosi Pre-Postnatale Malattie Metaboliche, IRCCS G. Gaslini, Genova, Italy;3Institute of Medical Genetics, School of Medicine, Cardiff University, Heath Park, Cardiff CF14 4XN. UK; ${ }^{4}$ Nanobiotecnologie, Istituto Nazionale per la Ricerca sul Cancro, Genova, Italy; ${ }^{5}$ Department of Metabolic Diseases, The Children's Memorial Health Institute, Warsaw, Poland; 6 Division of Genefics, Department of Pediatrics, Istanbul University, Cerrahpasa Faculty of Medicine, Istanbul, Turkey; ${ }^{7}$ Division of Pediatrics, Polytechnic University of the Marche, Ospedali Riuniti, Presidio Salesi, Ancona, Italy; ${ }^{8}$ Department of Pediatrics, University Children's Hospital, University of Padua, Italy; ${ }^{9}$ Telethon Institute of Genetics and Medicine, Napoli, Italy; ${ }^{10}$ Department of Pediatrics, Federico II University, Napoli, Italy; ${ }^{11}$ Department of Pediatric Sciences, Catholic University, Roma, Italy; ${ }^{2}$ Division of Metabolism, Hospital Infantil La Fe, Valencia, España;13S.S. Malattie Rare, U.O. Pediatria II, IRCCS G. Gaslini, Genova, Italy; ${ }^{14}$ Division of Metabolism, Bambino Gesù Children's Hospital, Roma, Italy:15Department of Pediatric Nutrition and Metabolism, Gazi University Medical School, Ankara, Turkey; ${ }^{16}$ Department of Genetics, Hospital Universitari Son Dureta, Palma de Mallorca, Spain; ${ }^{17}$ Department of Pediatrics, University of Milano Bicocca, San Gerardo Hospital, Monza, Italy

${ }^{*}$ Correspondence to:

Dr Francesca Bertola, Consortium for Human Molecular Genetics, Milano Bicocca University, (20052) Monza, Italy. Tel: +39 02 64488055; Fax: +39 02 64488361; E-mail: genemonza@unimib.it

Dr Mirella Filocamo, Lab Diagnosi Pre-Postnatale Malattie Metaboliche, Istituto G. Gaslini, Largo G. Gaslini 5 (16147) Genova, Italy. Tel: +39 010 5636792; Fax: +39 010 383983; E-mail: mirellafilocamo@ospedale-gaslini.ge.it

Communicated by Mark H. Paalman

ABSTRACT: Mutational analysis of the IDUA gene was performed in a cohort of 102 European patients with mucopolysaccharidosis type I. A total of 54 distinct mutant IDUA alleles were identified, 34 of which were novel including 12 missense mutations, 2 nonsense mutations, 12 splicing mutations, 5 micro-deletions, 1 micro-duplication 1 translational initiation site mutation, and 1 'no-stop' change (p.X654RextX62). Evidence for the pathological significance of all novel mutations identified was sought by means of a range of methodological approaches, including the assessment of evolutionary conservation, RT-PCR/in vitro splicing analysis, MutPred analysis and visual inspection of the 3D-model of the IDUA protein. Taken together, these data not only demonstrate the remarkable mutational heterogeneity characterizing type 1 mucopolysaccharidosis but also illustrate our increasing ability to make deductions pertaining to the genotype-phenotype relationship in disorders manifesting a high degree of allelic heterogeneity. C2011 Wiley-Liss, Inc.

KEY WORDS: IDUA, mucoplysaccharidosis type I, Hurler disease, genotype-phenotype analysis, molecular modelling, MutPred analysis, in vitro splicing analysis

Received 18 November 2010; accepted revised manuscript 7 February 2011.

(c) 2011 WILEY-LISS, INC. 


\section{Bertola et al.}

\section{INTRODUCTION}

Mucopolysaccharidosis type I (MPS I) is a rare autosomal recessive disorder resulting from deficiency of the lysosomal enzyme $\alpha$-L-iduronidase (IDUA; E.C. 3.2.1.76) which is involved in the degradation of the glycosaminoglycans (GAGs), namely heparan sulfate and dermatan sulfate. IDUA deficiency leads to the intralysosomal accumulation of undegraded GAG substrates and this coincides with the onset of pathology [Neufeld and Muenzer, 2001; Clarke, 2007]. Although the MPS-I clinical phenotype represents a continuous spectrum from the severe to the attenuated forms, three distinct phenotypes have been classically distinguished: 1) severe (Hurler syndrome, MPS IH; MIM\# 607014) when the onset of symptoms is before 12 months of age, with survival no more than 10 years and mental retardation manifesting before the age of three; 2) intermediate (Hurler/Scheie syndrome, MPS IH/S; MIM\# 607015) when onset of symptoms is between 1 and 6 years, survival is variable and mental retardation is absent or mild, but never before 3 years of age; and 3) 'attenuated' (Scheie syndrome, MPS IS; MIM\# 607016) when symptoms first become apparent after the age of 5, survival is normal and mental retardation is never present [Neufeld and Muenzer, 2001].

The gene encoding $\alpha$-L-iduronidase (IDUA; MIM\# 252800) maps to chromosome 4p16.3 and contains 14 exons; the cDNA open reading frame (ORF) is $\sim 2 \mathrm{~kb}$ in length and encodes a polypeptide of 653 amino acids (Scott et al., 1990, 1991, 1992). So far, more than 100 different disease-causing IDUA mutations have been reported (Human Gene Mutation Database; http://www.hgmd.org; Stenson et al., 2009). Several different types of mutation have been documented: whereas missense mutations may allow for some residual enzyme activity and are associated with quite a variable clinical phenotype, those mutations that are likely to impact upon RNA processing (i.e. nonsense, frameshift and splice site mutations) almost invariably result in a more severe phenotype [Terlato and Cox, 2003]. Non-pathogenic functional polymorphisms may also have a role in modifying the expression of IDUA mutant alleles, thereby contributing to the phenotypic and clinical heterogeneity characteristic of MPS I [Scott et al., 1995; Beesley et al, 2001; Matte et al., 2003].

Overall, most mutations are 'private', with only four mutations (p.W402X, p.Q70X, p.P533R, p.G51D) being common in specific populations. The most common IDUA mutation is $\mathrm{p} . \mathrm{W} 402 \mathrm{X}$ which has a frequency of around $50 \%$ in Northern Europe, the United Kingdom, North America [Beesley et al, 2001; Clarke et al., 1994; Scott et al., 1995] and Spain [Gort et al., 1998], while in Russia, Italy and Brazil its frequency has been estimated to be 4\% [Voskoboeva et al., 1998], 11\% [Gatti et al., 1997; Venturi et al., 2002] and 20\% [Matte et al., 2000], respectively . By contrast, the p.Q70X mutation is much more frequent in Scandinavia and Russia (around 50\% of alleles) than in other countries [Bunge et al., 1994; Voskoboeva et al., 1998]. The p.P533R mutation, which probably had a North African origin, has spread to Mediterranean countries, representing 13\% and $10 \%$ of IDUA mutant alleles in Italy and Spain respectively [Alif et al., 2000; Venturi et al., 2002; Voskoboeva et al., 1998]. Finally, the p.G51D mutation seems to be exclusively Italian with a relative frequency of $13 \%$ among IDUA mutant alleles [Venturi et al., 2002].

We have previously reported IDUA gene mutations from a series of 30 Italian patients [Venturi et al., 2002]. Here we have characterized the underlying IDUA mutations in a group of 102 newly studied European patients, including 37 Italians, whose condition has been clinically and biochemically diagnosed as MPS I.

\section{MATERIALS AND METHODS}

\section{Patients}

The present series comprises a total of 102 European patients (pts) affected by MPS I. They are from diverse ethnic backgrounds: 37 were of Italian origin, 23 Polish, 21 Turkish, 18 Spanish, and 3 patients each from Hungary, Serbia and Greece, (Table 1). The diagnosis of MPS I was confirmed biochemically in all patients, demonstrating a defect of IDUA activity either in leukocytes or a fibroblast cell line. As reported in Table 1, the clinical phenotype, defined as previously reported [Neufeld and Muenzer, 2003], was available for all but three patients: $59 \%$ of patients presented with the severe form of the disease (MPS IH), $22 \%$ with the intermediate form (MPS IH/S) and 15\% with the attenuated form (MPS IS); the remaining two patients (2\%) manifested a clinical phenotype ranging between MPS IH-H/S (pt \#43) and MPS IH/S-S (pt \#92).

Thirty seven Italian cases and one Serbian case were recruited with the help of their attending clinicians. The remaining 64 patients from different countries were recruited and collected through a collaboration with Genzyme Corporation (Cambridge, MA, USA) as part of a pan-European project with the aim of performing the molecular characterization of all MPS I patients in Europe and collecting these data in an MPS I Registry (https://www.lsdregistry.net/mpsiregistry) [Pastores et al., 2007]. 
2

Table 1. Clinical Phenotypes and Genotypes Encountered in 102 MPS Type 1 Patients with Distinct Ethnic Background

Table 1: Clinical Phenotypes and Genotypes Encountered in 102 MPS type I patients with distinct ethnic background

\begin{tabular}{|c|c|c|c|c|}
\hline $\mathrm{Pt}$ & Ethnic origin & Phenotype & Allele $1^{\S}$ & Allele $2^{5}$ \\
\hline 1 & Italy & $\mathrm{H} / \mathrm{S}$ & p.P496R & p.G265R \\
\hline 2 & Italy & $\mathrm{H}$ & p.A327P & p.A327P \\
\hline 3 & Italy & $\mathrm{H}$ & p.G51D & p.G51D \\
\hline 4 & Italy & $\mathrm{H}$ & p.Q70X & p.Q70X \\
\hline 5 & Italy & $\mathrm{H} / \mathrm{S}$ & p.G51D & p.P533R \\
\hline 6 & Italy & $\mathrm{H}$ & p.G51D & p.P496R \\
\hline 7 & Italy & $\mathrm{s}$ & p.G51D & p.R89W \\
\hline 8 & Italy & $\mathrm{H} / \mathrm{S}$ & p.P533R & p.P533R \\
\hline 9 & Italy & $\mathrm{H} / \mathrm{S}$ & p.Q70X & ? \\
\hline 10 & Italy & $\mathrm{H} / \mathrm{S}$ & p.W402X & p.L535F \\
\hline 11 & Italy & $\mathrm{H} / \mathrm{S}$ & p.W402X & p.E178K \\
\hline 12 & Italy & $\mathrm{s}$ & p.N348K & $c .1727+5 G>C$ \\
\hline 13 & Italy & $\mathrm{H} / \mathrm{S}$ & p.R89W & p.P496R \\
\hline 14 & Italy & $\mathrm{S}$ & p.G51D & c.1333_1335del3 \\
\hline 15 & Italy & $\mathrm{s}$ & p.Q70X & c.1333_1335del3 \\
\hline 16 & Italy & $\mathrm{H} / \mathrm{S}$ & p.[S423R;F188L] & p. [S423R;F188L] \\
\hline 17 & Italy & $\mathrm{H}$ & p.Q70X & p.P496R \\
\hline 18 & Italy & $\mathrm{H}$ & p.W402X & p.W402X \\
\hline 19 & Italy & $\mathrm{H}$ & c. $1727+1 G>A$ & p.P496R \\
\hline 20 & Italy & $\mathrm{H}$ & p.G51D & p.G51D \\
\hline 21 & Italy & $\mathrm{s}$ & p.Y581X & ? \\
\hline 22 & Italy & $\mathrm{H}$ & p.G51D & p.P496R \\
\hline 23 & Italy & $\mathrm{H}$ & p.Q70X & p.P496R \\
\hline 24 & Italy & $\mathrm{H}$ & c.46_57del12 & p.Y201X \\
\hline 25 & Italy & $\mathrm{H}$ & p.Q70X & p.Q70X \\
\hline 26 & Italy & $\mathrm{H}$ & $?$ & $?$ \\
\hline 27 & Italy & $\mathrm{H} / \mathrm{S}$ & c.46_57del12 & $c .1189+5 \mathrm{G}>\mathrm{A}$ \\
\hline 28 & Italy & $\mathrm{H}$ & c.380_382del3 & c.380_382del3 \\
\hline 29 & Italy & $\mathrm{s}$ & p.A327P & c.878_889dup \\
\hline 30 & Italy & $\mathrm{H}$ & p.Q.0X & p.P496R \\
\hline 31 & Italy & $\mathrm{H}$ & c.1166_1171dup & c.1166_1171dup \\
\hline 32 & Italy & $\mathrm{H} / \mathrm{S}$ & p.W402X & p.G265R \\
\hline 33 & Italy & $\mathrm{H}$ & p.Q70X & p.P496R \\
\hline 34 & Italy & $\mathrm{H}$ & p.T103P & $?$ \\
\hline 35 & Italy & $\mathrm{H}$ & p.Q70X & c.398_403del6 \\
\hline 36 & Italy & $\mathrm{H}$ & p.W402X & p.W402X \\
\hline 37 & Italy & $\mathrm{H}$ & p.P533R & ? \\
\hline $38 *$ & Poland & $\mathrm{H}$ & p.A327P & p.W402X \\
\hline 39 & Poland & $\mathrm{H}$ & p.Q70X & p.W402X \\
\hline 40 & Poland & $\mathrm{H}$ & p.Q.0XX & p.Q70X \\
\hline 41 & Poland & $\mathrm{H}$ & p.Q.07X & p.Q70X \\
\hline 42 & Poland & $\mathrm{H}$ & c.1045_1047del3 & c.1045_1047del3 \\
\hline 43 & Poland & $\mathrm{H}-\mathrm{H} / \mathrm{S}$ & p.Q70X & c.1045_1047del3 \\
\hline 44 & Poland & $\mathrm{S}$ & p.Q70X & p.G265R \\
\hline 45 & Poland & $\mathrm{S}$ & p.Q70X & c.46_57del12 \\
\hline 46 & Poland & $\mathrm{s}$ & p.Q70X & p.Y76C \\
\hline 47 & Poland & $\mathrm{H}$ & p.W402X & c. $1650+5 G>A$ \\
\hline 48 & Poland & $\mathrm{s}$ & c.46_57del12 & p.X654R \\
\hline 49 & Poland & $\mathrm{S}$ & c.878_889dup & c.1181_1189dup \\
\hline 50 & Poland & $\mathrm{H}$ & p.W402X & p.W402X \\
\hline 51 & Poland & $\mathrm{H}$ & p.W402X & c.1398delC \\
\hline 52 & Poland & $\mathrm{H}$ & p.Q70X & c. $972+2 \mathrm{~T}>\mathrm{C}$ \\
\hline
\end{tabular}

John Wiley \& Sons, Inc. 
4 Bertola et al.

2

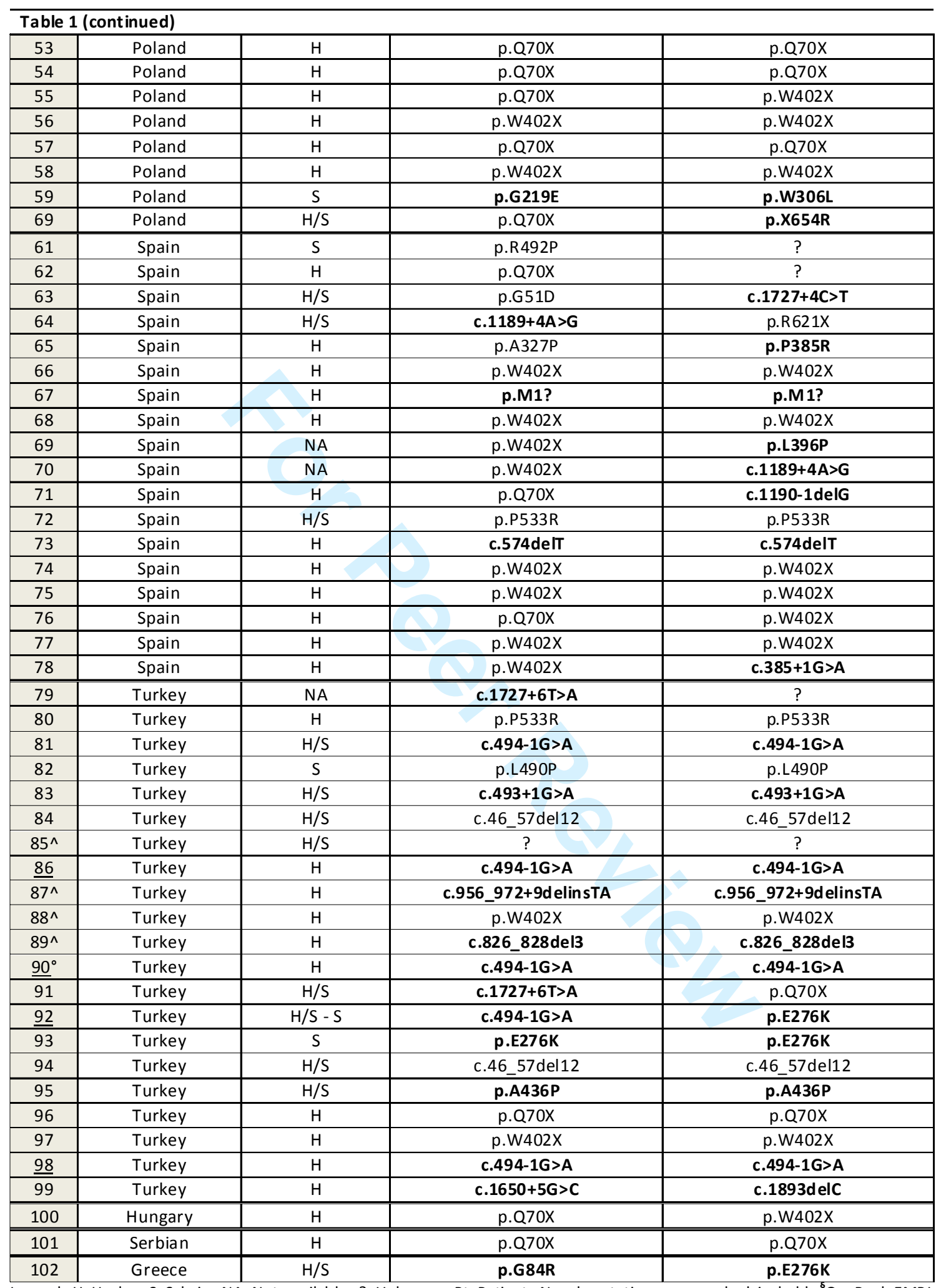

Legend: $\mathrm{H}=\mathrm{H}$ urler; $\mathrm{S}=$ Scheie; NA=Not available; ?=Unknown; Pt=Patient; Novel mutations are marked in bold. ${ }^{8}$ GenBank-EMBL accession no. NM_000203.3 (c.DNA considering the A of the ATG translation initiation start site as nucleotide +1 ) and GenBankEMBL accession no. NP_000194 (protein); *Patient not analysed in our Lab; ^indicates parents' consanguinity; ${ }^{\circ}$ Patient's parents belonging to the same village; Underlined patients belonging to the same geographical region 
Some of the samples from the Italian patients were supplied by the "Cell line and DNA Biobank from patients affected by Genetic Diseases" in Genova (http://dppm.gaslini.org/biobank/). Following ethical guidelines, all samples obtained for analysis and storage required prior written informed consent using a form approved by the Local Ethics Committee.

\section{Cell culture}

Fibroblast cells were cultured according to standard procedures. The cell lines were cultured and maintained in RPMI medium (EuroClone, Gibco, Paisley, UK) containing 15\% FCS and penicillin/streptomycin, in a humidified atmosphere containing $5 \% \mathrm{CO}_{2}$ at $37^{\circ} \mathrm{C}$.

\section{Enzymatic assay}

$\alpha$-L-iduronidase activity was assayed in homogenates of leukocytes and/or fibroblast cell lines using 4methylumbelliferyl- $\alpha$-L-iduronide (Glycosynth, Cheshire, UK) as a substrate [Stirling et al., 1978]. Total protein was measured according to the Lowry method [Lowry et al., 1951].

\section{Molecular analysis}

Genomic DNA was extracted from circulating lymphocytes and/or cultured fibroblasts using either the Wizard Genomic DNA Purification kit (Promega, Madison, WI) or a standard phenol-chloroform-based method.

IDUA gene exons, exon-intron boundaries and part of the 5' untranslated region were PCR amplified using specific primers designed by reference to the genomic sequence (GenBank-EMBL Accession no. NG_008103.1). Intronic primers, designed for both PCR and sequence analyses, are listed in Supp. Table S1. PCR amplification reactions (except for exon 9) were carried out in $25 \mu \mathrm{l}$ vols containing 100ng genomic DNA, buffer 1X with $1.5 \mathrm{mM} \mathrm{MgCl} 2,200 \mu \mathrm{M}$ dNTPs mix, $15 \mathrm{pmol}$ each primer, GC-RICH solution $1 \mathrm{X}$ and $0.5 \mathrm{U}$ proofreading PWO SuperYield DNA polymerase (Roche, Monza, Italy). Exon 9 PCR-amplification was carried out in $25 \mu$ vols containing 100ng genomic DNA, buffer $1 \mathrm{X}$ with $1.5 \mathrm{mM} \mathrm{MgCl} 2,200 \mu \mathrm{M}$ dNTPs mix, $15 \mathrm{pmol}$ each primer and 0.5U GoTaq DNA polymerase (Promega, Madison, WI); owing to the use of a no-proofreading DNA polymerase, this reaction was performed in duplicate. Cycling conditions were: initial denaturation at $96^{\circ} \mathrm{C}$ for 5 min, 28 cycles denaturation at $96^{\circ} \mathrm{C}$ for $1 \mathrm{~min}$, annealing at $63-70^{\circ} \mathrm{C}$ for $1 \mathrm{~min}$, extension at $72^{\circ} \mathrm{C}$ for $1 \mathrm{~min}$, followed by final extension at $72^{\circ} \mathrm{C}$ for $7 \mathrm{~min}$. Control PCR reactions, in which no template was added, were included during each set of PCR reactions. PCR products were controlled for contamination by gel electrophoresis and were then purified using an enzymatic reaction containing $5 \mathrm{U}$ exonuclease I (Celbio, Italy) and $1 \mathrm{U}$ alkaline phosphatase (Promega, Madison, WI) under the following conditions: $15 \mathrm{~min}$ at $37^{\circ} \mathrm{C}$ followed by $15 \mathrm{~min}$ at $80^{\circ} \mathrm{C}$.

Total RNA was prepared from peripheral blood lymphocytes isolated by the Fycoll method or from cultured fibroblasts using Trizol Reagent (Gibco, Paisley, UK) according to the manufacturer's instructions. First-strand cDNAs were synthesized using the High-Capacity cDNA Reverse Transcription Kit (Applied Biosystems, Foster City, CA) and random hexamer primers. IDUA exonic fragments flanking splicing mutations were amplified and sequenced using primers and conditions listed in Supp. Table S1.

Sequence analysis of PCR and RT-PCR products was performed in the forward and reverse directions using BigDye v3.1 terminator technology (Applied Biosystems, Foster City, CA) and then purified with Wizard MagneSil Sequencing Reaction Clean-Up System (Promega, Madison, WI). Sequencing reactions were carried out, the products purified according to the manufacturer's instructions and analyzed on an ABI Prism 3130 Avant Automatic Sequencer (Applied Biosystems, Foster City, CA). Sequence alterations were confirmed by sequencing duplicate PCR products.

The question of the pathological authenticity of the novel IDUA sequence alterations detected was addressed by (i) searching dbSNP (http://www.ncbi.nlm.nih.gov/SNP) for their presence, (ii) screening 100 alleles from healthy control subjects for each alteration, (iii) modeling the amino acid changes into a homologous three-dimensional structure of the protein, (iv) employing the MutPred program [Li et al., 2009; Mort et al., 2010] for the missense mutations, (v) using ESRPred and a neural network for splice site prediction [Krawczak et al., 2007] for the coding region variants upon splicing, and (vi) using PhyloP method [Pollard et al., 2010] and ClustalW2 program [Larkin et al., 2007] to measure evolutionary conservation of nucleotides and residues, respectively. 


\section{Bertola et al.}

\section{Molecular modeling of missense mutations}

For modeling of the IDUA missense mutations, an homology model of the IDUA protein was used. This model was built by Rempel et al. (2005) using the atomic coordinates of $\beta$-xylosidase (E.C.3.2.1.37) from Thermoanaerobacterium saccharolyticum as a template [PDB code 1Y24]. Visual inspection and graphical representations were then performed using the programs Coot and Chimera, respectively [Emsley and Cowtan, 2004; Pettersen et al., 2004].

\section{Bioinformatic analysis of IDUA variants}

Missense variants in the IDUA gene were analysed with a computational model, MutPred [Li et al., 2009, Mort et al., 2010]. MutPred is designed to assess the likely phenotypic consequences of missense substitutions occurring within sites of structural and/or functional importance, on the wild-type protein sequence. MutPred can be used to generate hypotheses as to the underlying molecular mechanism(s) responsible for disease pathogenesis.

The effect of the coding region variants upon splicing [splice site disruption, cryptic splice site activation and exon skipping via loss of exonic splicing enhancers (ESE) and/or gain of exonic splicing silencers (ESS)] was ascertained using ESRPred [M. Mort, unpuplished] and a neural network for splice site prediction [Krawczak et al., 2007].

Evolutionary sequence conservation across an alignment of IDUA orthologues from 44 vertebrate species was measured using the phyloP method [Pollard et al., 2010]. PhyloP can measure accelerated evolution (more rapid evolution than expected under neutral drift) as well as evolutionary conservation (slower than expected evolution). A positive phyloP score represents an evolutionarily conserved nucleotide and a negative phyloP score indicates that the nucleotide has experienced more rapid evolution than would be expected under neutral drift.

\section{Mutation nomenclature}

Mutations are described according to current mutation nomenclature guidelines (http://www.hgvs.org/mutnomen), ascribing the A of the first ATG translational initiation codon as nucleotide +1 [den Dunnen and Antonarakis, 2000; den Dunnen and Paalman, 2003].

\section{RESULTS AND DISCUSSION}

A total of 102 European patients affected by MPS I were recruited by our centre. All patients underwent molecular characterization and the IDUA genotype was completely ascertained in 93 of the 102 patients.

\section{Mutation detection}

All 14 exons, splice junctions and proximal portions of the 5' and 3' untranslated regions of the IDUA genes of the 102 unrelated MPS I patients were investigated by DNA sequence analysis. Putatively pathological IDUA mutations were identified in 193 of 204 alleles. The genotypes, clinical phenotypes and geographic origins of the 102 patients studied here are listed in Table 1. The characteristics of the 55 distinct IDUA mutations identified are reported in Table 2. The mutational spectrum comprised 22 missense mutations, 14 splice site alterations, 9 microdeletions, 5 nonsense mutations, 3 micro-duplications, 1 translational initiation site mutation and 1 no-stop mutation. More than $60 \%(35 / 55)$ of these mutant alleles have not been previously reported, attesting to the extensive allelic heterogeneity of MPS I. The novel lesions resulted from (i) 11 missense mutations (p.Y76C, p.G84R, p.T103P, p.G219E, p.E276K, p.W306L, p.N384K, p.P385R, p.L396P, p.A436P, p.L535F) as well as two missense mutations located in cis to each other (p.[F188L;S423R]); (ii) 12 splicing mutations (c.385+1G>A, c. $493+1 \mathrm{G}>\mathrm{A}$, c. $494-1 \mathrm{G}>\mathrm{A}$, c.956 972+9delinsTA, c. $1189+4 \mathrm{~A}>\mathrm{G}$, c. $1189+5 \mathrm{G}>\mathrm{A}$, c.1190-1delG, c.1650+5G $>$ C, c. $1727+1 \mathrm{G}>\mathrm{A}$, c. $1727+4 \mathrm{C}>\mathrm{T}$, c. $1727+5 \mathrm{G}>\mathrm{C}, \mathrm{c} .1727+6 \mathrm{~T}>\mathrm{A}$ ); (iii) 5 micro-deletions (c.574delT, c.826_828del3, c.1045_1047del3, c.1398delC and c.1893delC), 1 micro-duplication (c.1166_1171dup), 2 nonsense mutations (p.201X and p.Y581X), 1 translational initiation site mutation (p.M1?) and 1 'no-stop' mutation (p.X654RextX62). 
2

In addition to these putative pathological mutations, a total of 37 putative intragenic IDUA polymorphisms were identified within either the exons or introns; eight novel SNPs were noted within the coding region (4) and in the introns (4) (Supp. Table S2). The allele frequencies of the novel variants, derived from 100 normal control alleles, are given in Supp. Table S2. Figure 1 depicts the location of the various mutations and polymorphisms detected in relation to the structure of the IDUA gene.

\section{Table 2. Characteristics of the IDUA gene mutations identified in the 102 MPS type I patients and MutPred analysis of the missense mutations}

\begin{tabular}{|c|c|c|c|c|c|c|c|c|}
\hline \multirow[b]{2}{*}{ Loc. } & \multirow[b]{2}{*}{$\begin{array}{l}\text { Site of nucleotide } \\
\text { substitution* }\end{array}$} & \multirow{2}{*}{$\begin{array}{c}\text { Predicted effect on } \\
\text { protein struc ture } \\
* *\end{array}$} & \multirow[b]{2}{*}{$\begin{array}{l}\text { Type of } \\
\text { mutation }\end{array}$} & \multirow{2}{*}{$\begin{array}{l}\text { No. of } \\
\text { alleles } \\
(\%)\end{array}$} & \multirow{2}{*}{\begin{tabular}{|c|} 
Evolutionary \\
Conservation \\
(phyloP)
\end{tabular}} & \multicolumn{2}{|c|}{ MutPred analysis of missense mutations \# } & \multirow[b]{2}{*}{ References } \\
\hline & & & & & & \begin{tabular}{|c|} 
Deleterious \\
mutation \\
probability
\end{tabular} & $\begin{array}{c}\begin{array}{c}\text { Sum mary of con fident in silico } \\
\text { hypotheses }\end{array} \\
\end{array}$ & \\
\hline \multirow{3}{*}{ Ex. 1} & c. $1 \mathrm{~A}>\mathrm{C}$ & p.M1? & \begin{tabular}{|l|} 
Translational \\
in itiation site
\end{tabular} & $2(0.01)$ & $\operatorname{Acc}(-0.3)$ & 0.99 & & Present study ${ }^{5}$ \\
\hline & c.152G $>A$ & p.G51D & Missense & $10(4.9)$ & Cons (2.7) & 0.97 & Protein structure disruption & Bunge et al. (1994) \\
\hline & c.46_57d el12 & p.S16_A19del & In-frame del & $8(3.9)$ & &. & & Bunge et al. (1994) \\
\hline \multirow{4}{*}{ Ex. 2} & c. $208 \mathrm{C}>\mathrm{T}$ & p.Q70X & Nonsense & $38(18)$ & Cons (2.1) & . & & Scott et al. (1992) \\
\hline & c.227A $>G$ & p.Y76C & Missense & $1(0.05)$ & Cons (2.7) & 0.73 & & Present study \\
\hline & c.250G>C & p.G84R & Missense & $1(0.05)$ & Cons (5.5) & 0.93 & $\begin{array}{l}\text { Gain of binding site and disruption to } \\
\text { protein structure }\end{array}$ & Present study \\
\hline & c. $265 \mathrm{C}>\mathrm{T}$ & p.R89W & Missense & $2(0.01)$ & Cons (0.3) & 0.96 & & Bunge et al. (1995) \\
\hline \multirow{2}{*}{ Ex. 3} & c. $.307 \mathrm{~A}>\mathrm{C}$ & p.T103P & Missense & $1(0.05)$ & Cons $(0.4)$ & 0.36 & & Present study \\
\hline & c.380_382del3 & p.L127del & In-frame del & $2(0.01)$ & &. & & Venturi et al. (2002) \\
\hline Intr. 3 & $\mathrm{c} .385+1 \mathrm{G}>\mathrm{A}$ & r.spl? & Splicing & $1(0.05)$ & Cons (5.1) & . & & Present study \\
\hline Ex. 4 & c.398_403del6 & p.M133_G134del & In-frame del & $1(0.05)$ & & . & & Venturi et al. (2002) \\
\hline \multirow{2}{*}{ Intr. 4} & c. $493+1 \mathrm{G}>\mathrm{A}$ & r.spl? & Splicing & $2(0.01)$ & Cons (6.2) & . & & Present study \\
\hline & c.494-1G>A & p.R166TfsX27 & Splicing & $9(4.4)$ & Cons (5.7) & . & & Present study \\
\hline \multirow{3}{*}{ Ex. 5} & c.532G>A & p.E178K & Missense & $1(0.05)$ & Cons (4.5) & 0.97 & Gain of functional sites including PTMs & Venturi et al. (2002) \\
\hline & c. $[562 \mathrm{~T}>\mathrm{C} ; 1269 \mathrm{C}>\mathrm{A}]^{+}$ & p. $[\text {F188L;S423R }]^{+}$ & Missense & $2(0.01)$ & Cons $(3.0 ; 1.2)$ & $0.95 ; 0.92$ & Gain of methylation at $\mathrm{S} 423$ & Present study \\
\hline & c.574d elT & p.S192PfsX2 & Frameshift & $2(0.01)$ & &. & & Present study \\
\hline \multirow{2}{*}{ Ex. 6} & c. $603 \mathrm{C}>\mathrm{G}$ & p.Y201X & Non sense & $1(0.05)$ & Cons $(0.7)$ & . & & Present study \\
\hline & c.656G $>A$ & p.G219E & Missense & $1(0.05)$ & Cons (5.9) & 0.89 & \begin{tabular}{|c|} 
Protein structure disruption \\
\end{tabular} & Present study \\
\hline \multirow{5}{*}{ Ex. 7} & c.793G $>C$ & p.G265R & Missense & $3(1.4)$ & Cons (6.2) & 0.95 & $\begin{array}{l}\text { Secon dary struct ure disruption, gain of } \\
\text { methylation at G265 }\end{array}$ & Yogalingam et al.(2004) \\
\hline & c.826G >A & p.E276K & Missense & $4(1.9)$ & Cons (6.2) & 0.76 & & Present study \\
\hline & c.826_828del3 & p.E276del & In-frame del & $2(0.01)$ & & . & & Present study \\
\hline & c.878_889dup & p.T293_Y296dup & In-frame dup & $2(0.01)$ & . & . & & Bunge et al. (1995) \\
\hline & c.956_972+9delinsTA & r.spl? & Splicing & $2(0.01)$ &. & . & & Present study \\
\hline Intr. 7 & c. $972+2 \mathrm{~T}>\mathrm{C}$ & r.spl? & Splicing & $1(0.05)$ & Cons (1.6) &. & & Scott et al. (1993) \\
\hline \multirow{8}{*}{ Ex. 8} & $\mathrm{c} .917 \mathrm{G}>\mathrm{T}$ & p.W306L & Missense & $1(0.05)$ & Cons (6.0) & 0.82 & Loss of catalytic residue at P309 & Present study \\
\hline & $979 \mathrm{G}>\mathrm{C}$ & p.A327P & Missense & $5(2.4)$ & Cons (1.2) & 0.84 & $\begin{array}{c}\text { Protein structure disruption and gain } \\
\text { of methylation at } \mathrm{K} 324\end{array}$ & Bunge et al. (1995) \\
\hline & c. $1044 \mathrm{C}>\mathrm{G}$ & p.N348K & Missense & $1(0.05)$ & $\operatorname{Acc}(-0.4)$ & 0.85 & $\begin{array}{c}\text { Decrease in protein stability and gain } \\
\text { of PTMs }\end{array}$ & Present study \\
\hline & c.1045_1047 del3 & p.D349del & In-frame del & $3(1.4)$ & - & . & $x_{1}^{2}$ & Present study \\
\hline & c. $1154 \mathrm{C}>\mathrm{G}$ & p.P385R & Missense & $1(0.05)$ & Cons (5.4) & 0.82 & Protein structure disruption & Presentstudy \\
\hline & c.1166_1171dup & p.A389_M390dup & In-frame dup & $2(0.01)$ & & . & & Present study \\
\hline & c.1187T $>C$ & \begin{tabular}{|l|l|} 
p.L396P \\
\end{tabular} & Missense & $1(0.05)$ & Cons (3.1) & 0.83 & $\begin{array}{l}\text { Decrease in protein stability and } \\
\text { secondary struct ure disruption }\end{array}$ & Present study \\
\hline & c.1181_1189dup & p.A394_L396dup & In-frame dup & $1(0.05)$ & & . & & Bunge et al. (1995) \\
\hline \multirow{3}{*}{ Intr. 8} & $c .1189+4 A>G$ & p.V371MfsX43 & Splicing & $2(0.01)$ & Cons (4.3) & . & & Present study \\
\hline & c. $1189+5 \mathrm{G}>\mathrm{A}$ & p.V371MfsX43 & Splicing & $1(0.05)$ & Cons (2.9) & . & & Present study \\
\hline & c.1190-1delG & r.spl? & Splicing & $1(0.05)$ & - & . & . & Present study \\
\hline & c. $1205 \mathrm{G}>\mathrm{A}$ & p.W 402X & Nonsense & $37(18)$ & Cons (1.8) & . & & Scott et al. (1992) \\
\hline Ex 9 & c. $1306 \mathrm{G}>\mathrm{C}$ & p.A436P & Missense & $2(0.01)$ & Cons (2.8) & 0.45 & & Present study \\
\hline & c.1333_1335del3 & p.D445 del & In-frame del & $2(0.01)$ & &. & & Bunge et al. (1995) \\
\hline & c.1398d elC & p.P467RfsX58 & Frameshift & $1(0.05)$ & & . & & Present study \\
\hline & c. $1469 \mathrm{~T}>\mathrm{C}$ & p.L490P & Missense & $2(0.01)$ & Cons $(0.4)$ & 0.86 & $\begin{array}{l}\text { Decrease in protein stability and } \\
\text { protein structure disruption }\end{array}$ & Tieu et al. (1995) \\
\hline Ex. 10 & c. $1475 \mathrm{G}>\mathrm{C}$ & p.R492P & Missense & $1(0.05)$ & Cons (0.7) & 0.83 & Loss of binding site & Tieu et al. (1995) \\
\hline & c. $1487 C>G$ & p.P496R & Missense & $9(4.4)$ & Cons (4.4) & 0.95 & Gain of bin ding site & Beesley et al. (2001) \\
\hline & c. $1598 \mathrm{C}>\mathrm{G}$ & p.P533R & Missense & $8(3.9)$ & Cons (4.1) & 0.94 & Gain of bin ding site & Scott et al. (1992) \\
\hline Ex. 11 & c. $1603 C>T$ & p.L535F & Missense & $1(0.05)$ & Cons (1.7) & 0.59 & & Present study \\
\hline Intr 11 & c. $1650+5 \mathrm{G}>\mathrm{A}$ & r.spl? & Splicing & $1(0.05)$ & Cons (4.7) & . & & Venturi et al. 2002 \\
\hline Intr. I1 & c. $1650+5 \mathrm{G}>\mathrm{C}$ & r.spl? & Splicing & $1(0.05)$ & Cons (4.7) & . & & Present study \\
\hline & c. $1727+1 \mathrm{G}>\mathrm{A}$ & r.spl? & Splicing & $1(0.05)$ & Cons (3.8) &. & & Present study \\
\hline & c. $1727+4 C>T$ & p.L578V fsX14 & Splicing & $1(0.05)$ & Cons (0.4) & . & & Present study \\
\hline Intr. 12 & c. $1727+5 G>C$ & Exon 12 skipping & Splicing & $1(0.05)$ & Cons (5.4) &. & & Present study \\
\hline & c. $1727+6 T>A$ & Exon 12 skipping & Splicing & $2(0.01)$ & Cons (1.1) & . & & Present study \\
\hline Ex. 13 & c. $1743 \mathrm{C}>\mathrm{G}$ & p.Y581X & Nonsense & $1(0.05)$ & $\operatorname{Acc}(-1.1)$ & . & & Present study \\
\hline & c. $1861 \mathrm{C}>\mathrm{T}$ & p.R621X & Nonsense & $1(0.05)$ & Cons (1.5) & . & & Bunge et al. (1994) \\
\hline Ex. 14 & c.1893delC & p.F632SfsX105 & Frameshift & $1(0.05)$ & & . & & Present study \\
\hline & c. $1960 \mathrm{~T}>\mathrm{C}$ & p.X654RextX62 & No-stop & $2(0.01)$ & $\operatorname{Acc}(-0.4)$ & . & & Present study \\
\hline
\end{tabular}

Legend: Loc= Location; Ex=exon; Intr=intron; del=deletion; dup=duplication; Acc= Accelerated; Cons= Conserved; PTMs= Post-translational modifications *IDUA gene GenBank-EMBL accession no. NM_000203.3; **IDUA gene GenBank-EMBL accession no. NP_000194; the novel mutations are given in bold; \#Li et al. (2009) and Mort et al. (2010). ${ }^{+}$Allele carrying 2 novel mutations in cis; note that the second change occurs in exon 9 and it was previously reported as single allele as due to $c .1269 \mathrm{C}>\mathrm{G}$ by Yogalingam et al. (2004); ${ }^{5}$ mutation previously reported as due to a c.3G>A by Le e-Chen and Wang (1997) 
8 Bertola et al.

2

3

4

5

6

7

8

9

10

\section{Missense mutations}

A total of 14 novel IDUA missense mutations were detected during the course of this study; two being located in cis on the same IDUA allele (p.[F188L;S423R]). Consistent with their putative pathological authenticity, none of the underlying nucleotide changes were found in a screen of 100 control alleles. Nor were any of these substitutions listed as polymorphisms in dbSNP (http://www.ncbi.nlm.nih.gov/projects/SNP).

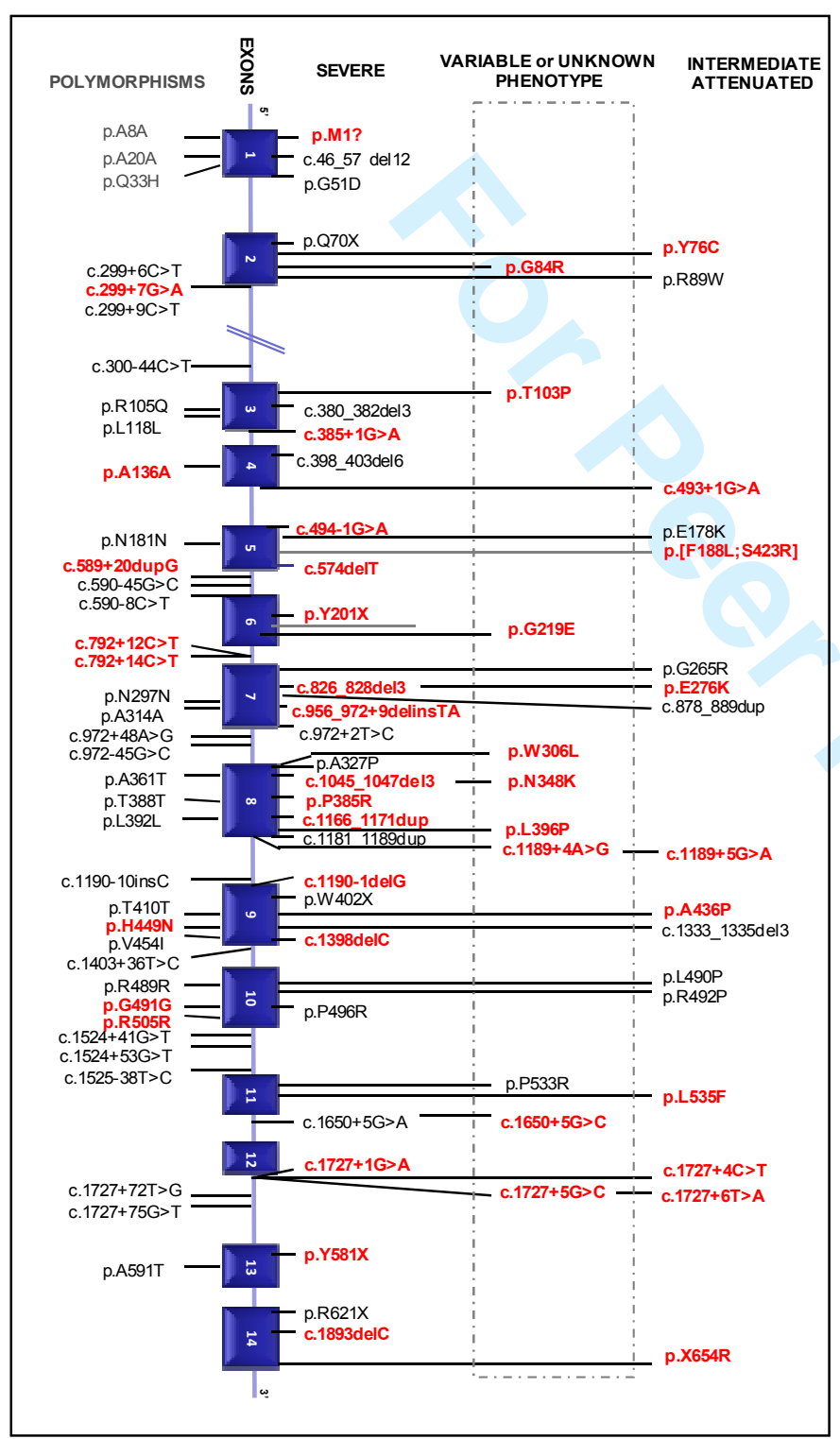

Figure 1. Distribution of the 54 detected mutant alleles and 37 putatively neutral polymorphisms in relation to the structure of the IDUA gene. The schematic map of the IDUA gene depicts the positions of the 14 numbered exons (blue boxes) and associated unnumbered introns (blue lines). An indication of the clinical phenotype associated with each of the 54 different mutant alleles identified in the 102 patients is provided. Thus, on the right of the diagram are listed those mutations associated with severe and attenuated (intermediate+mild) phenotypes respectively. Mutations associated with variable or unknown clinical phenotypes are given in the gray dotted box. On the left of the diagram, the polymorphic variants detected during the course of this study are listed. Novel alleles (34) and novel polymorphic variants (8) are marked in red.

\section{Bioinformatic analysis of missense variants}

MutPred predicted that most of the missense mutations listed in Table 2 are deleterious $(91 \% ; 21$ out of 23; MutPred general score $>50$ ). Further, confident in silico hypotheses for the underlying mechanism of pathogenesis were generated for 14 of the missense mutations (summarised in Table 2 and reported in full in Supp. Table S3). The two missense mutations (p.T103P and p.A436P) predicted not to be deleterious by MutPred, were analysed 
further (Supp. Table S4). PhyloP scores were used to measure evolutionary conservation at the nucleotide sequence level across IDUA orthologues derived from 44 vertebrate species. Both mutations (p.T103P and p.A436P) exhibited positive phyloP scores indicating that these mutations are located at conserved nucleotides. It should be noted that p.T103P displays only marginal conservation, with a phyloP score of 0.40 . Analysis with SIFT [Ng and Henikoff, 2001] predicted that both mutations would be tolerated in the protein. PolyPhen2 [Adzhubei et al., 2010] however predicted that whilst p.T103P was benign, p.A436P mutation was likely to be potentially damaging. Neither mutation was predicted to disrupt splicing using a neural network [Krawczak et al., 2007]. MutPred analysis was also performed on the six polymorphic missense variants identified (listed in Supp. Table S2) but none of these were predicted to be deleterious (MutPred general scores invariably $<50$ ).

Further evidence for the pathological/functional significance of the missense mutations was then sought from the analysis of the extent of evolutionary conservation of the mutated residues in 6 orthologous (vertebrate) IDUA proteins from human to Tetraodon nigroviridis. The computational analysis, carried out using ClustalW2 [http://www.ebi.ac.uk/clustalw; Larkin et al., 2007], revealed that among the 5 other vertebrate IDUA protein sequences examined, Y76, G84, F188, G219, R276, W306, N348, P385, L396, S423, L535 were invariant at these positions; such conservation over 500 Myrs of evolutionary time is supportive of the functional significance of these residues and hence the direct involvement of the respective mutations in disease causation. In agreement with the PolyPhen score results, residue A436 was found to be partially conserved (chimpanzee, dog and chicken) but T103 was not evolutionarily conserved. (Supp. Figure S1). It may be that the p.A436P mutation is mildly deleterious, whereas p.T103P may be tolerated and could therefore represent a rare polymorphism.

\section{D modelling of IDUA missense mutations}

To shed further light on the deleterious consequences of the novel missense IDUA mutations at the protein level, we employed the homology model of IDUA constructed by Rempel et al. [2005]. Since the IDUA model starts at residue 36 and terminates at residue 522, the p.L535F substitution could not be included in this analysis. As shown in Figure 2, and detailed in Supp. Table S5, several substitutions (p.G219E, p.P385R and p.S423R) appear to affect a hydrophobic buried region in the protein, one substitution occurs in the predicted active site residue (p.F188L), and one substitution in the active site cleft (p.W306L) [Rempel et al., 2005]. The remaining amino acid replacements (p.G84R, p.Y76C, p.T103P, p.E276K, p.N348K, p.L396P and p.A436P) affected solvent accessible residues. Consistent with previous findings [Rempel et al., 2005; Vazna et al., 2009; Sugawara et al., 2008], those mutations that occur in the protein core (including the predicted active site), were associated with the severe (H) form of MPS I, whereas the missense mutations which affected surface-located residues were associated with the more attenuated clinical phenotypes (H/S, S) (Figure 2 and Supp. Table S5). Despite obtaining data from both structural and bioinformatic analyses, the pathological significance of the p.T103P, which occurs in a long loop of unknown function that protrudes into the solvent, remains unclear.

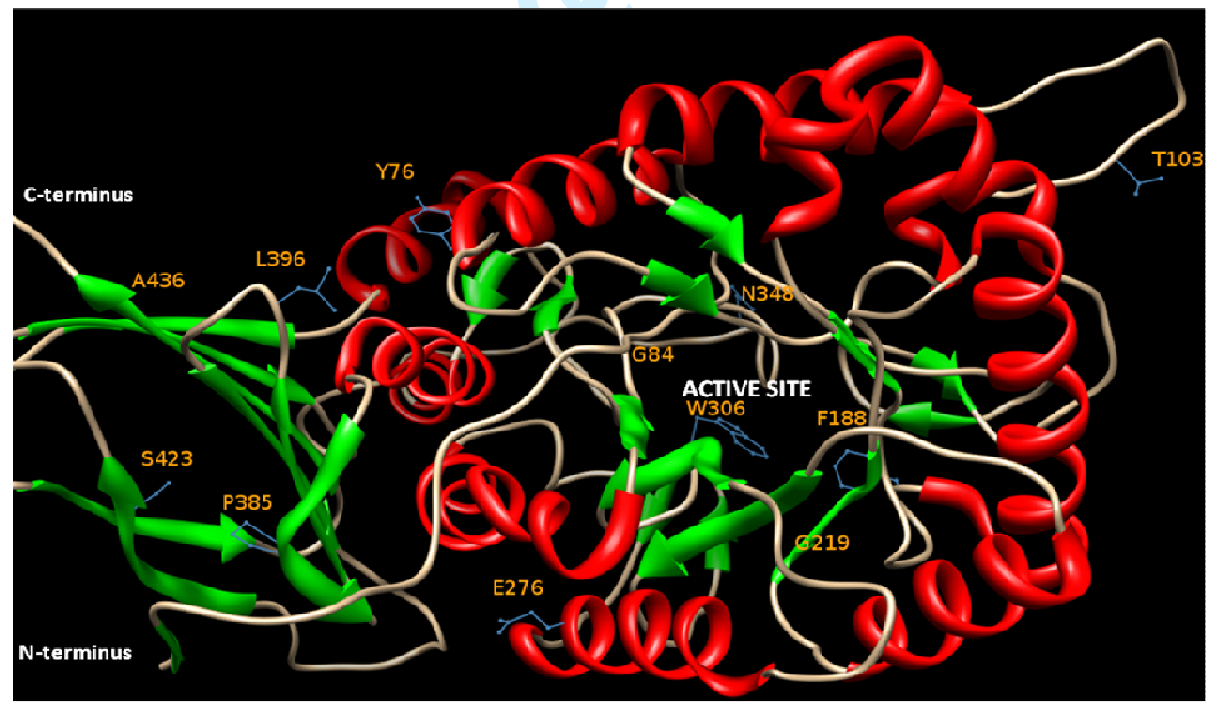

Figure 2. Ribbon representation of the three dimensional structure of (the homology model of) wild-type IDUA [Rempel et al., 2005]. The $\alpha$ helices are colored red and the $\beta$ sheets green; the wild-type residues analysed are depicted as blue sticks. 
10 Bertola et al.

\section{Splicing mutations}

A substantial proportion of the novel IDUA mutations detected $(34.3 \%)$ occurred in either the donor (c.385+1G $>$ A, c. $493+1 \mathrm{G}>\mathrm{A}$, c. $1727+1 \mathrm{G}>\mathrm{A})$ or acceptor $(\mathrm{c} .494-1 \mathrm{G}>\mathrm{A}$, c.1190-1delG) splice sites or in the surrounding splicing motifs $($ c. $1189+4 \mathrm{~A}>\mathrm{G}, \quad$ c. $1189+5 \mathrm{G}>\mathrm{A}, \quad$ c. $1650+5 \mathrm{G}>\mathrm{C}, \quad$ c. $1727+4 \mathrm{C}>\mathrm{T}, \quad$ c. $1727+5 \mathrm{G}>\mathrm{C}$, c. $1727+6 \mathrm{~T}>\mathrm{A}$ ) (Table 2). All the single base-pair substitutions predicted to disrupt splicing were located at nucleotides which were evolutionarily conserved across an alignment of IDUA gene sequences from 44 vertebrate species. We also identified an indel mutation (c.956_972+9delinsTA) as the cause of aberrant splicing in one case. At the genomic level, the mutation comprised the deletion of 26 nucleotides and the insertion of the dinucleotide $\mathrm{TA}$ in a region overlapping the exon-intron 7 donor splice site.

Supp. Figure S2 graphically represents the intronic location of the 12 novel splicing mutations identified in MPS I patients in the present study. To assess the potential effect of these mutations on mRNA splicing, the relative strengths of the 5' and 3 ' splice site signals were evaluated using the NetGene2 server [http://www.cbs.dtu.dk/services/NetGene2]. According to this program, all 12 mutations would be predicted to impact upon RNA processing. In particular, donor splice sites would have been abrogated in the presence of c. $385+1 \mathrm{G}>\mathrm{A}, \mathrm{c} .493+1 \mathrm{G}>\mathrm{A}, \mathrm{c} .1650+5 \mathrm{G}>\mathrm{C}, \mathrm{c} .1727+1 \mathrm{G}>\mathrm{A}, \mathrm{c} .1727+5 \mathrm{G}>\mathrm{C}$ and c. $1727+6 \mathrm{~T}>\mathrm{A}$ as would acceptor sites in the presence of $c .494-1 \mathrm{G}>\mathrm{A}$ and $\mathrm{c} .1190-1 \mathrm{delG}$. The same analysis predicted a considerable decrease in the donor splice site confidence score in the cases of c. $1189+4 \mathrm{~A}>\mathrm{G}, \mathrm{c} .1189+5 \mathrm{G}>\mathrm{A}$ and c. $1727+4 \mathrm{C}>\mathrm{T}$.

These predictions were then followed up by performing in vitro splicing analysis for those mutations identified in patients from whom appropriate samples were available. The functional relevance of six intronic mutations (c.494-1G>A, c. $1189+4 \mathrm{~A}>\mathrm{G}$, c. $1189+5 \mathrm{G}>\mathrm{A}$, c. $1727+4 \mathrm{C}>\mathrm{T}, \mathrm{c} .1727+5 \mathrm{G}>\mathrm{C}$ and c. $1727+6 \mathrm{~T}>\mathrm{A}$ ) was assessed by carrying out reverse transcriptase-polymerase chain reaction (RT-PCR) analysis on mRNA extracted from either lymphocytes ( $3 \mathrm{pts}$ ) or fibroblast cell lines ( $3 \mathrm{pts}$ ). In the case of c. $1727+5 \mathrm{G}>\mathrm{C}$ and c. $1727+6 \mathrm{~T}>\mathrm{A}$, the RT-PCR results clearly confirmed the abrogation of the expected donor splice site leading to the skipping of exon 12 or the activation of alternative splice sites (exonic or intronic) leading to frameshifts with consequent premature truncation of the protein (p.Y167TfsX, p.V371MfsX, p.L578VfsX). Full details are given in Table 3.

\section{Table 3. Summary of the results of the reverse transcriptase-PCR analysis on mRNA samples}

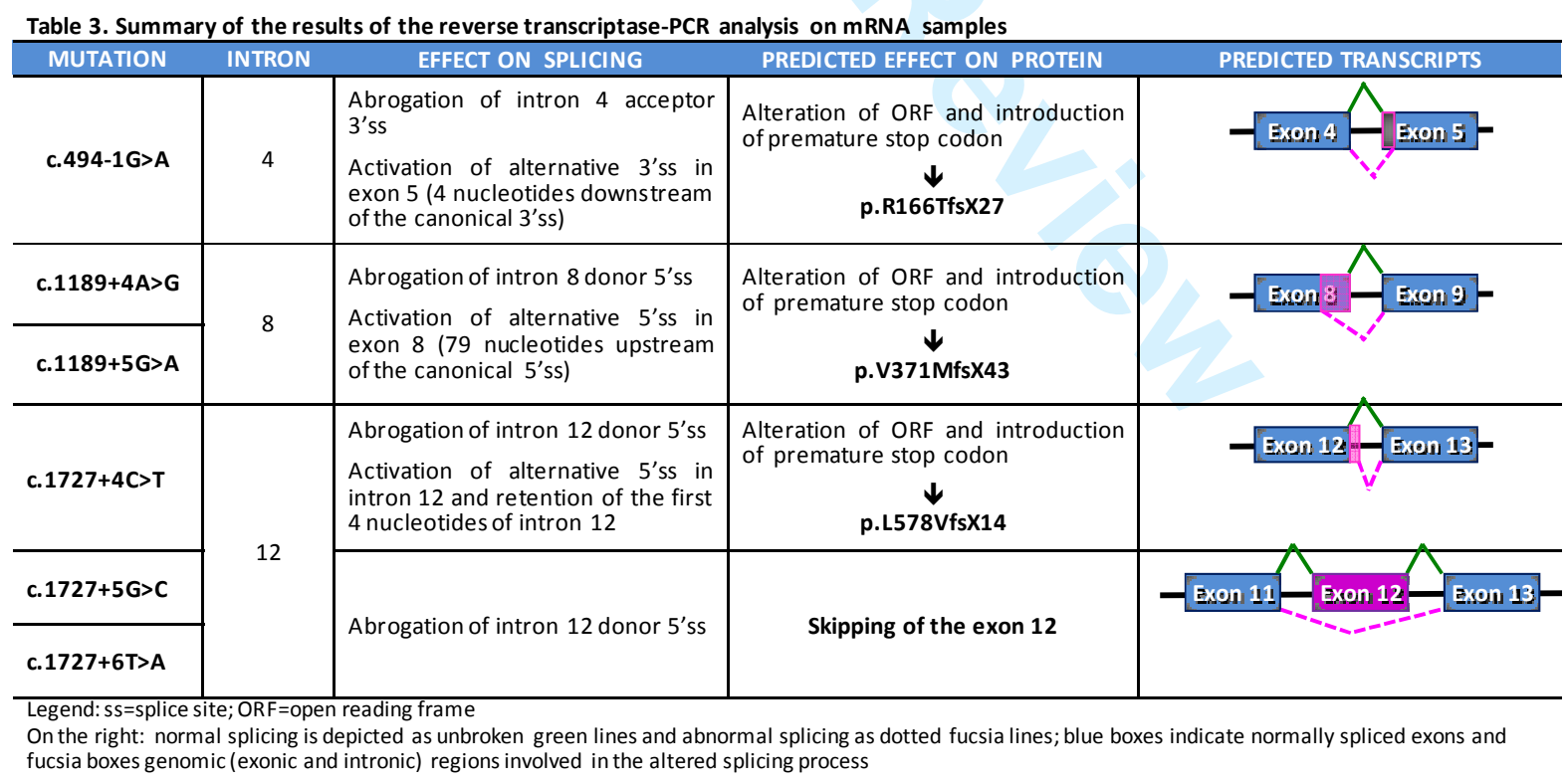

John Wiley \& Sons, Inc. 


\section{Genotype-phenotype relationship}

Genotypes, clinical phenotypes and geographic origins of the 102 patients studied here are listed in Table 1. Some $45(44 \%)$ of the patients (pts) were found to be either homozygous for the pan-ethnic IDUA mutations, p.W402X (12 pts), p.Q70X (9 pts) and p.P533R (3 pts), other known mutations (7 pts) or novel lesions (14 pts).

The remaining $54 \%$ of patients were compound heterozygotes (including 7 in whom the second mutant IDUA allele could not be identified). Finally, the mutant IDUA alleles in two patients (2\%), in whom a defect in IDUA enzyme activity had been documented, remained unidentified.

Overall, we found 68 distinct genotypes including those (7) that were partially characterized. Our results confirm the high degree of mutational heterogeneity characteristic of MPS I. Extensive allelic heterogeneity often precludes the recognition of correlations between mutant genotypes and variant clinical phenotypes. This notwithstanding, in an attempt to obtain new insights into the genotype-phenotype relationship in MPS I, we have compared the genotypes present in our patient series with those of previously reported patients. Supp. Table S6, reports the comparable genotypes (13/68) and the respective number of patients per genotype reported in previous studies on this topic.

Among the analyzed group, 25 patients were either homozygous or compound heterozygous for the two common deleterious nonsense mutations (p.Q70X and p.W402X); their severe clinical phenotype concurred with those of 91 previously reported patients with comparable genotypes [Bunge et al., 1994; Gort et al., 1998; Hein et al., 2003; Li et al., 2002; Matte et al., 2003; Scott et al., 1992; Vazna et al., 2009; Venturi et al., 2002; Voskoboeva et al. 1998]. In agreement with previously reported genotype-phenotype correlations, a severe phenotype was not only associated with the p.W402X mutation in compound heterozygosity with both c. $1650+5 \mathrm{G}>\mathrm{A}$ and $\mathrm{p}$. A327P [Bunge et al., 1994; Venturi et al., 2002; Vazna et al., 2009] but also with homozygosity for p.A327P and p.G51D [Gatti et al., 1997]. Also consistent with previous data [Beesley et al, 2001; Tieu et al., 1995 ], homozygosity for p.L490P and compound heterozygosity for p.Q70X and c.1333_1335del3 yielded mild phenotypes in two other patients (Supp. Table S6). Although for these 38 patients (37\%), the predicted genotype-phenotype relationship may be considered informative, for the remaining group with previously described genotypes, the correlations only partially concurred (Supp. Table S6). This latter group comprised 6 patients, 3 of whom were homozygous either for the p.P533R mutation or for the microdeletion c.46_57del12 (2 pts), and another patient who was compound heterozygous for p.G51D and p.P533R. Comparison between the genotype-phenotype correlation data from our 6 patients and 23 patients from other studies [Alif et al., 1999; Hein et al., 2003; Gatti et al., 1997; Hein et al., 2003, Laradi et al., 2005; Matte et al., 2003; Scott et al., 1992; Venturi et al., 2002] confirmed the phenotypic variability of these mutations (p.P533R and c.46_57del12). Similarly, in our patient series (Table 1), these two latter mutations (p.P533R and c.46_57del12), although present in both the homozygous or compound heterozygous state, and in a significant number of individuals (viz. pts \#5, \#8, \#37, \#72, \#80 and pts \#24, \#27, \#45, \#48, \#84, \#94, respectively), were found to be associated with a wide range of clinical severity.

Additional conclusions were drawn by individually comparing some mutations in our series (Table 1) with those from previous studies. According to Hein et al. [2003], mildly deleterious consequences could be confirmed for the mutation p.R89W, contributing to the mild form of MPS I noted in pts \#7 and \#13, in whom this allele was in association with the already known severe mutations, p.G51D and p.P496R, respectively. In our own patients, this latter allele (p.P496R) was invariably found to be associated with the severe form of MPS I (pts \#6, \#17, \#19, $\# 22, \# 23, \# 30, \# 33$ ); this finding confirms the assessment of its detrimental nature, made in vitro, by Beesley et al. [2001]. The only patient harbouring p.P496R to exhibit an intermediate clinical form of MPS I (pt \#1) was a compound heterozygote in whom the clinical effect of this detrimental allele was probably attenuated by the relative benign influence of p.G265R. In support of this latter supposition was the compound heterozygosity (p.G265R+p.Q70X) observed in the Scheie patient \#44 (Table 1). Conversely, conclusions as to the genotypephenotype relationship manifested by mutation c.494-1G>A, found in either the homozygous (pts \#81, \#86, \#90, $\# 98$ ) or compound heterozygous ( $\mathrm{pt} \mathrm{\# 92)} \mathrm{state,} \mathrm{were} \mathrm{equivocal} \mathrm{since} \mathrm{this} \mathrm{lesion} \mathrm{was} \mathrm{associated} \mathrm{with} \mathrm{very} \mathrm{different}$ degrees of clinical severity, even in patients who appeared to share the same genetic background (Table 1). It may be that other genetic or non-genetic factors can modulate the clinical phenotype in MPS I. Among the possible genetic factors involved, as previously reported in the same MPS I [Yogalingam et al., 2004] or in other MPSs such as MPS II [Lualdi et al., 2006], are differentially spliced-RNA transcripts that might result from the splicing mutation c.494-1G $>$ A, and could potentially be considered as modifiers of the clinical phenotype [Nissim-Rafinia and Kerem, 2002]. Unfortunately, RNA samples were not available to permit experimental verification. 
2

Another factor limiting our ability to define effective genotype-phenotype correlations was probably our difficulty in attributing one or other clinical phenotype in a given case, bearing in mind that the clinical spectrum of disease in MPS I is in reality a continuum of phenotypes with gradually changing severity. This is particularly true for the so called 'intermediate form', where it is difficult to be truly objective, especially when the patients are young at the time of diagnosis and there is no standardized scoring index of severity.

\section{Frequency and geographical distribution of common and rare mutations in the European polulation}

As reported in Table 2, in the whole series comprising patients with diverse genetic backgrounds, the frequency of the most common mutations was: p.Q70X (18.6\%), p.W402X (18\%), p.G51D (4.9\%), p.P496R (4.4\%) p.P533R (3.9\%), p.A327P (2.4\%) and c.46_57del12 (3.9\%). Altogether, they represented 56\% of IDUA alleles. Rare or private mutations comprised $49.5 \%$ of IDUA lesions, and $28.4 . \%$ of these were novel. However, when we analysed the geographical distribution and relative frequencies of the five most frequent mutations in different areas of Europe, we observed significant differences in the distribution of these mutations (Figure 3).

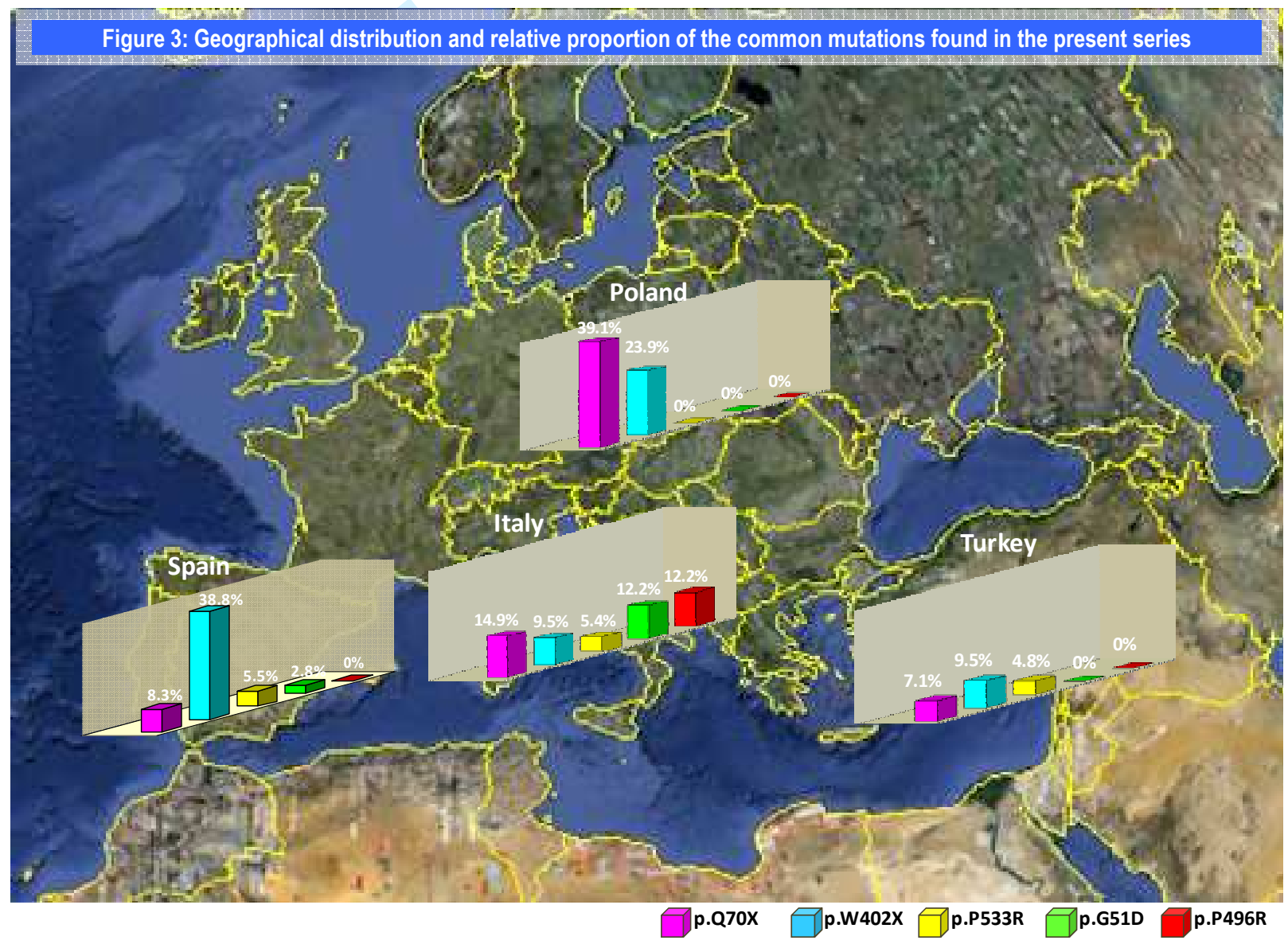

Figure 3. Geographical-distribution and relative proportion of the common mutations found in the present series.

In Western Europe, the most frequent mutation was p.W402X, representing 38.8\% of alleles in Spain. Although its relative frequency in the other Mediterranean countries decreased sharply to $9.5 \%$ in both Italy and Turkey, p.W402X maintained a relatively high frequency in Northern Europe, accounting for $24 \%$ of IDUA alleles in our series of patients from Poland. Conversely, the p.Q70X mutation accounted for 39\% of IDUA alleles in Poland but progressively decreased in terms of its frequency in a Southerly direction, constituting $14.9 \%$ in Italy, $8.3 \%$ in Spain and $7.1 \%$ in Turkey. On the basis of these results, and supported by previous data [Terlato and Cox, 2003], it could be speculated that the European geographical diffusion of $\mathrm{p}$.W402X occurred from the South-West in a Northerly direction, while that of p.Q70X occurred from the North-East in a Southerly direction. Mediterranean countries appear to have balanced the relatively low frequency of these two common mutations with other 
mutations specific to this geographical region viz. p.P533R, p.P496R and p.G51D, the latter two being specific to (and recurrent in) the Italian population, and c.494-1G>A, a Turkish-specific mutation (not shown in the figure). The relatively low frequency of the two usually common mutations (p.Q70X and p.W402X) in Italy and Turkey, results in an increase in IDUA allelic heterogeneity in these two countries as compared to Northern European countries. Thus, rare mutations accounted for $50 \%$ and $71.4 \%$ of alleles in Italy and Turkey, respectively, as compared to Poland and Spain where they were $37 \%$ and $41.6 \%$ respectively. The finding that European countries vary widely in terms of both the distribution and frequency of IDUA gene mutations has important implications for the selection of screening strategies in individual countries. The existence of dramatic differences in mutational heterogeneity and mutation prevalence highlights the importance of multi-national screening studies in helping to elucidate the genotype-phenotype relationship in disorders such as MPS I that are characterized by extensive allelic heterogeneity.

\section{ACKNOWLEDGMENTS}

European patient samples were obtained through a collaboration with Genzyme Corporation, Cambridge, MA, USA. Some samples were also obtained from the "Cell Line and DNA Biobank from Patients Affected by Genetic Diseases" (G. Gaslini Institute) - Telethon Genetic Biobank Network (Project No. GTB07001A). We also thank Prof. Generoso Andria (Napoli), Dr. Rita Barone (Catania), Prof. Cesare Danesino (Pavia), Prof. Paola Di Natale (Napoli), Dr. Graziella Uziel (Milano), for their contribution of clinical information and patient samples.

\section{REFERENCES}

Adzhubei IA, Schmidt S, Peshkin L, Ramensky VE, Gerasimova A, Bork P, Kondrashov AS, Sunyaev SR. 2010. A method and server for predicting damaging missense mutations. Nat Methods 7:248-249.

Alif N, Hess K, Straczek J, Sebbar S, Belahsen Y, Mouane N, Abkari A, Nabet P, Gelot MA. 2000. Mucopolysaccharidosis type I in Morocco: clinical features and genetic profile. Arch Pediatr 7:597-604.

Beesley CE, Meaney CA, Greenland GA, Adams V, Vellodi A, Young EP, Winchester BG. 2001. Mutational analysis of 85 mucopolysaccharidosis type I families: frequency of known mutations, identification of 17 novel mutations and in vitro expression of missense mutations. Hum Genet 109:503-511.

Bunge S, Kleijer WJ, Steglich C, Beck M, Schwinger E, Gal A. 1995. Mucopolysaccharidosis type I: identification of 13 novel mutations of the alpha-L-iduronidase gene. Hum Mutat 6:91-94.

Bunge S, Kleijer WJ, Steglich C, Beck M, Zuther C, Morris CP, Schwinger E, Hopwood JJ, Scott HS, Gal A. 1994. Mucopolysaccharidosis type I: identification of 8 novel mutations and determination of the frequency of the two common alpha-L-iduronidase mutations (W402X and Q70X) among European patients. Hum Mol Genet 3:861-866.

Cartegni L, Chew SL, Krainer AR. 2002. Listening to silence and understanding nonsense: exonic mutations that affect splicing. Nat Rev Genet 3:285-298.

Clarke LA, Nelson PV, Warrington CL, Morris CP, Hopwood JJ, Scott HS. 1994. Mutation analysis of 19 North American mucopolysaccharidosis type I patients: identification of two additional frequent mutations. Hum Mutat 3:275-282.

Clarke LA (Updated [September 21, 2007]). Mucopolysaccharidosis Type I. In: GeneReviews at GeneTests: Medical Genetics Information Resource (database online). Copyright, University of Washington, Seattle. 1993-2007. Available at http://www.genetests.org

den Dunnen JT, Antonarakis SE. 2000. Mutation nomenclature extensions and suggestions to describe complex mutations: a discussion. Hum Mutat 15:7-12.

den Dunnen JT, Paalman MH. 2003. Standardizing mutation nomenclature: why bother? Hum Mutat 2:181-182.

Emsley, P. \& Cowtan, K. 2004. Coot: model-building tools for molecular graphics. Acta Crystallogr. D 60:2126-2132

John Wiley \& Sons, Inc. 


\section{Bertola et al.}

Gatti R, DiNatale P, Villani GR, Filocamo M, Muller V, Guo XH, Nelson PV, Scott HS, Hopwood JJ. 1997. Mutations among Italian mucopolysaccharidosis type I patients. J Inherit Metab Dis 20:803-806.

Gort L, Chabas A, Coll MJ. 1998. Analysis of five mutations in 20 mucopolysaccharidosis type 1 patients: high prevalence of the W402X mutation. Hum Mutat 11:332-333.

Hein LK, Hopwood JJ, Clements PR, Brooks DA. 2003. The alpha-L-iduronidase mutations R89Q and R89W result in an attenuated mucopolysaccharidosis type I clinical presentation. Biochim Biophys Acta 1639:95-103.

Krawczak M, Thomas NS, Hundrieser B, Mort M, Wittig M, Hampe J, Cooper DN. 2007. Single base-pair substitutions in exon-intron junctions of human genes: nature, distribution, and consequences for mRNA splicing. Hum Mutat 28:150-158.

Laradi S, Tukel T, Erazo M, Shabbeer J, Chkioua L, Khedhiri S, Ferchichi S, Chaabouni M, Miled A, Desnick RJ. 2005. Mucopolysaccharidosis I: alpha-L-Iduronidase mutations in three Tunisian families. J Inherit Metab Dis 28:1019-1026.

Larkin M.A., Blackshields G., Brown N.P., Chenna R., McGettigan P.A., McWilliam H., Valentin F., Wallace I.M., Wilm A., Lopez R., Thompson J.D., Gibson T.J. and Higgins D.G. 2007. ClustalW and ClustalX version 2. Bioinformatics 23(21): 2947-2948.

Li B, Krishnan VG, Mort ME, Xin F, Kamati KK, Cooper DN, Mooney SD, Radivojac P. 2009. Automated inference of molecular mechanisms of disease from amino acid substitutions. Bioinformatics 25:2744-2750.

Li P, Wood T, Thompson JN. 2002. Diversity of mutation and distribution of single nucleotide polymorphic alleles in the human alpha-L-iduronidase (IDUA) gene. Genet Med 4:420-426

Lowry OH, Rosebrough NJ, Farrand AL, Randall RJ. 1951. Protein measurement with the Folin-Phenol reagents. J Biol Chem 193:265-275.

Lualdi S, Pittis MG, Regis S, Parini R, Allegri A, Furlan F, Bembi B, Filocamo M. 2006. Multiple cryptic splice sites can be activated by $I D S$ point mutations generating misspliced transcripts. J Mol Med 84:692-700.

Matte U, Yogalingam G, Brooks D, Leistner S, Schwartz I, Lima L, Norato DY, Brum JM, Beesley C, Winchester B, Giugliani R, Hopwood JJ. 2003. Identification and characterization of 13 new mutations in mucopolysaccharidosis type I patients. Mol Genet Metab 78: 37-43.

Mort M, Evani US, Krishnan VG, Kamati KK, Baenziger PH, Bagchi A, Peters BJ, Sathyesh R, Li B, Sun Y, Xue B, Shah NH, Kann MG, Cooper DN, Radivojac P, Mooney SD. 2010. In silico functional profiling of human disease-associated and polymorphic amino acid substitutions. Hum Mutat 31:335-346.

Nalla VJ and Rogan PK. 2005. Automated splice site analysis by information theory. Hum Mut 25:334-342.

Neufeld EF, Muenzer J. 2001 The mucopolysaccharidoses. in Scriver CR, Beaudet AL, Sly WS, Valle D (eds): The metabolic and molecular bases of inherited disease, 8th Ed McGraw-Hill, , New York pp 3421-3452.

Ng PC, Henikoff S. 2001. Predicting deleterious amino acid substitutions. Genome Res. 11:863-874.

Nissim-Rafinia M, Kerem B. 2002. Splicing regulation as a potential genetic modifier. Trends Genet 18:23-27

Pastores GM, Arn P, Beck M, Clarke JT, Guffon N, Kaplan P, Muenzer J, Norato DY, Shapiro E, Thomas J, Viskochil D, Wraith JE. 2007. The MPS I registry: design, methodology, and early findings of a global disease registry for monitoring patients with mucopolysaccharidosis type I. Mol Genet Metab 91:37-47.

Pettersen EF, Goddard, TD, Huang CC, Couch GS, Greenblatt DM, Meng EC, Ferrin TE. 2004. UCSF Chimera - a visualization system for exploratory research and analysis. J Comput. Chem. 25:1605-1612.

Pollard KS, Hubisz MJ, Rosenbloom KR, Siepel A. 2010. Detection of nonneutral substitution rates on mammalian phylogenies. Genome Res. 20:110-121.

Rempel BP, Clarke LA, Withers SG. 2005. A homology model for human $\alpha$-1-iduronidase: Insights into human disease. Mol Genet Metab 85:28-37

Scott HS, Anson DS, Orsborn AM, Nelson PV, Clements PR, Morris CP, Hopwood JJ. 1991. Human alpha-L-iduronidase: cDNA isolation and expression. Proc Natl Acad Sci USA 88:9695-9699. 
Scott HS, Ashton LJ, Eyre HJ, Baker E, Brooks DA, Callen DF, Sutherland GR, Morris CP, Hopwood JJ. 1990. Chromosomal localization of the human alpha-L-iduronidase gene (IDUA) to 4p16.3. Am J Hum Genet 47:802-807.

Scott HS, Bunge S, Gal A, Clarke LA, Morris CP. Hopwood JJ. 1995. Molecular genetics of mucopolysaccharidosis type I: diagnostic, clinical, and biological implications. Hum Mutat 6:288-302.

Scott HS, Guo XH, Hopwood JJ, Morris CP. 1992. Structure and sequence of the human alpha-L-iduronidase gene. Genomics 13: 1311-1313.

Scott HS, Litjens T, Nelson PV, Brooks DA, Hopwood JJ, Morris CP. 1992. alpha-L-iduronidase mutations (Q70X, and P533R) associate with a severe Hurler phenotype. Hum Mutat 1:333-339.

Scott HS, Litjens T, Nelson PV, Thompson PR, Brooks DA, Hopwood JJ, Morris CP. 1993. Identification of mutations in the alpha -L-lduronidase gene (IDUA) that cause Hurler and Scheie syndromes. Am J Hum Genet 53:973-986.

Stenson PD, Mort M, Ball E, Howells K, Phillips A, Thomas NST, Cooper DN. 2009. The Human Gene Mutation Database: 2008 update. Genome Med 1:13.

Stirling JL, Robinson D, Fensom AH, Benson PF, Baker JE. 1978. Fluorimetric assay for prenatal detection of Hurler and Scheie homozygotes or heterozygotes. Lancet. 1:147.

Sugawara K, Saito S, Ohno K, Okuyama T, Sakuraba H. 2008. Structural study on mutant alpha-L-iduronidases: insight into mucopolysaccharidosis type I. J Hum Genet 53:467-474.

Terlato NJ, Cox GF. 2003. Can mucopolysaccharidosis type I disease severity be predicted based on a patient's genotype? A comprehensive review of the literature. Genet Med 5:286-294.

Tieu PT, Bach G, Matynia A, Hwang M, Neufeld EF. 1995. Four novel mutations underlying mild or intermediate forms of alpha-L-iduronidase deficiency (MPS IS and MPS IH/S). Hum Mutat 6:55-59.

Vazna A, Beesley C, Berna L, Stolnaja L, Myskova H, Bouckova M, Vlaskova H, Poupetova H, Zeman J, Magner, Hlavata A, Winchester B, Hrebicek M, Dvorakova L. 2009. Mucopolysaccharidosis type I in 21 Czech and Slovak patients: mutation analysis suggests a functional importance of C-terminus of the IDUA protein. Am J Med Genet Part A 149A:965-974.

Venturi N, Rovelli A, Parini R, Menni F, Branbillasca F, Bertagnolio F, Uziel G, Gatti R, Filocamo M, Donati MA, Biondi A, Goldwurm S. 2002. Molecular analysis of 30 mucopolysaccharidosis type I patients: evaluation of the mutational spectrum in Italian population and identification of 13 novel mutations. Hum Mutat 20:231.

Voskoboeva E, Krasnopolskaya X, Mirenburg T, Weber B, Hopwood J. Molecular genetics of mucopolysaccharidosis type I: mutation analysis among the patients of the former Soviet Union. Mol Genet Metab 1998;65:174-180

Yogalingam G, Guo X, Muller V, Brooks DA, Clements PR, Kakkis ED, Hopwood JJ. 2004. Identification and molecular characterization of alpha-L-iduronidase mutations present in mucopolysaccharidosis type I patients undergoing enzyme replacement therapy. Hum Mutat 24: 199-207. 
16 Bertola et al.

2

3

4

SUPPORTING INFORMATION

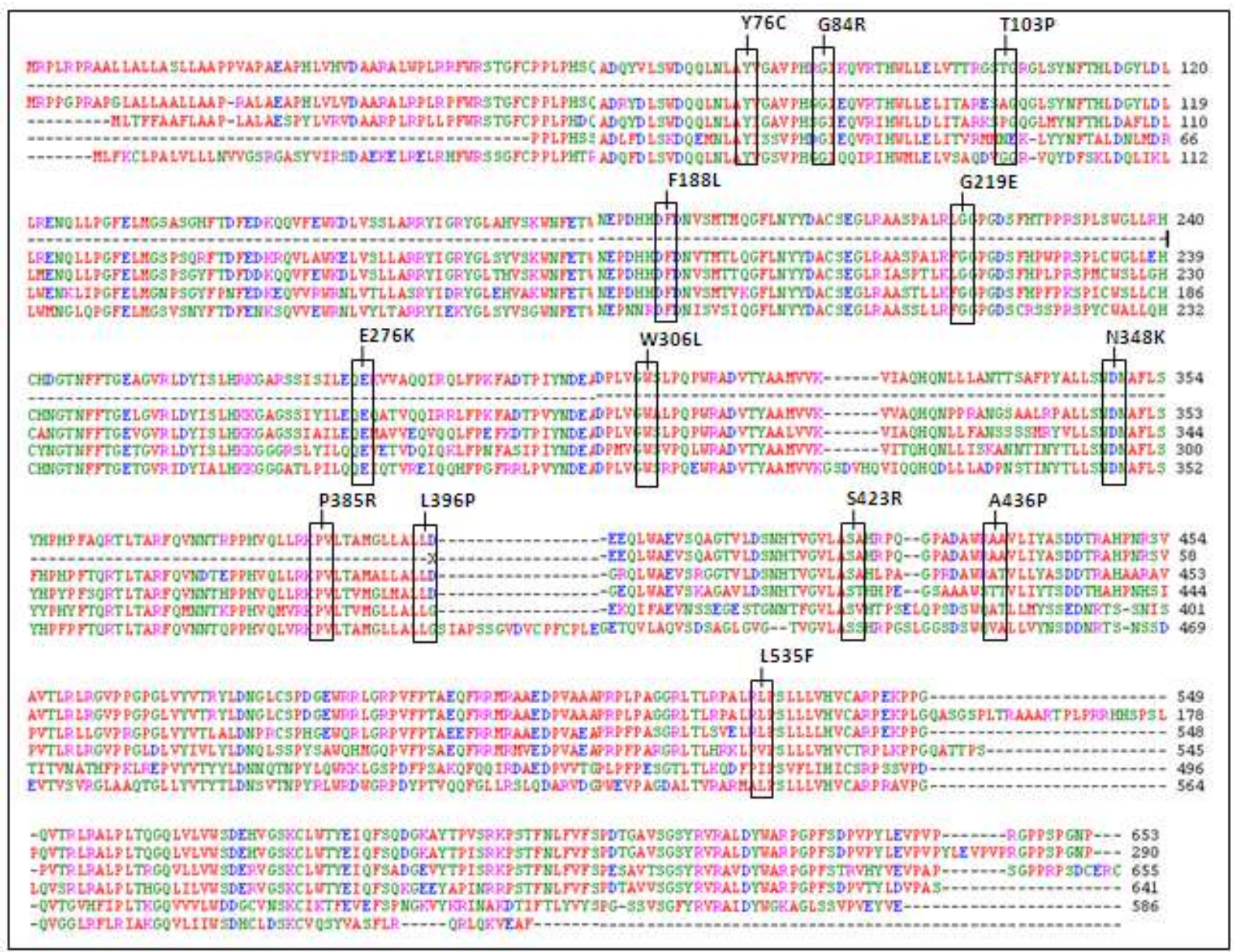

Supp. Figure S1. Evolutionary comparison of the protein sequences flanking the missense mutations identified in the human IDUA protein with their orthologous counterparts in 5 vertebrates (in silico data from http://www.ebi.ac.uk/clustalw/). From the top: From the top: Homo sapiens, Pan troglodytes, Canis familiaris, Mus musculus, Gallus gallus, Tetraodon nigrovisidis. Positions of mutations are marked by vertical boxes. Note that the translational initiation site substitution, predicted to produce either no protein or to move the initiation site up/downstream (p.M1?), was excluded from the analysis. 
Supp. Table S1. List of primers used for polymerase chain reaction (PCR) amplification of IDUA gene exons and exonintron boundaries

\begin{tabular}{|c|c|c|c|c|c|c|}
\hline $\begin{array}{c}\text { Exons } \\
\text { amplified }\end{array}$ & Forward $\left(5^{\prime}>3^{\prime}\right)^{*}$ & Nucleotide position & Reverse $\left(5^{\prime}>3^{\prime}\right)^{*}$ & $\begin{array}{c}\text { Nucleotide } \\
\text { position }^{a}\end{array}$ & $\begin{array}{l}\text { PCR product } \\
\text { size (bp) }\end{array}$ & $\begin{array}{c}\text { Annealing } \\
\text { Temperature } \\
\left({ }^{\circ} \mathrm{C}\right)\end{array}$ \\
\hline \multicolumn{7}{|c|}{ Genomic DNA Amplification $^{a}$} \\
\hline 1 & AGGCGGAACCGGCAGTGCAG & g.5035-5054 & TCCGGTCTCTGAAGCTCTCA & g.5338-5319 & 304 & 67 \\
\hline 2 & CGCTGCCAGCCATGCTGAGGCTCG & g.5760-5783 & ACAAGGGGTCTTCCGAGC & g.6045-6028 & 286 & 67 \\
\hline $3-4 * *$ & ATCGGAGTCCTGTGTGGCACCT & g.18497-18518 & TGCCCACCAATGTATCTCCTGA & g.19101-19080 & 605 & 65 \\
\hline 5 & CATCACCTTGCACCCTCC & g.19391-19408 & CGTCTACACCTGCCCTGG & g.19663-19646 & 273 & 65 \\
\hline 6 & GAGGAAGGCAGGAGCAGAG & g.19611-19629 & CTCAGCACCACCAGGGTC & g.19969-19952 & 359 & 65 \\
\hline $7-8^{* *}$ & TGCGGCTGGACTACATCTC & g.19854-19872 & CTGGAGGAAGTGCGCTCC & g.20584-20567 & 731 & 63 \\
\hline$* * *$ & CCACCTTCCTCCCGAGAC (8F) & g.20199-20216 & AGTAGCAGGTTCTGATGCTGC (7R) & g.20301-20281 & - & - \\
\hline $9-10^{* *}$ & TCCTTCACCAAGGGGAGG & g.20631-20648 & TCCTCAGGGTTCTCCAGG & g.21331-21314 & 701 & 63 \\
\hline$* * *$ & GGTGACCCTGCGGCTG (10F) & g.20911-20926 & CTGACACTCAGGCCTCGG (9R) & g.21030-21013 & - & - \\
\hline $11-12^{* *}$ & GTGTGGGTGGGAGGTGGA & g.21244-21261 & GAGCCCGAATGTCCATCTCATGTC & g.21853-21830 & 610 & 67 \\
\hline $13-14 * *$ & GGGCTTGAGGGAATGAGG & g.21911-21928 & GGTGATGGGAGGGCAGCA & g.22483-22466 & 573 & 65 \\
\hline \multicolumn{7}{|c|}{ cDNA Amplification $^{\text {b }}$} \\
\hline $3-4-5$ & CGGCATCTTGCTGGTCCGGACCC & c.337-359 & CGCTGTCCCTCCGAGCAGGC & c.717-698 & 381 & 65 \\
\hline $8-9$ & GGGCTGGTCCCTGCCACAGC & c.1000-1019 & CGTTGTCCAGGTAGCGCGTGAC & c.1523-1502 & 524 & 67 \\
\hline $12-13-14$ & TGCTGGTGCACGTGTGTGCGC & c. $1695-1715$ & ATGGGAGGGCAGCATGGGCAC & c. $2132-2112$ & 474 & 67 \\
\hline
\end{tabular}

IDUA gene: 'GenBank-EMBL accession no. NG_008103.1; ' GenBank-EMBL accession no. NM_000203.3; * the primers are located 5' (upstream) and 3' (downstream) to the intronic sequences flanking each exon; ${ }^{*}$ in this case, the size also includes intronic regions; ${ }^{* * *}$ internal primers used for sequencing 
18 Bertola et al.

2

3

4

5

6

Supp. Table S2: Characteristics of putatively neutral SNPs identified in the IDUA gene

\begin{tabular}{|c|c|c|c|c|c|c|}
\hline \multirow[b]{2}{*}{ Location } & \multirow[b]{2}{*}{$\begin{array}{c}\text { dbSNP } \\
\text { no. }\end{array}$} & \multirow[b]{2}{*}{$\begin{array}{c}\text { Site of nucleotide } \\
\text { substitution* } \\
\text { (amino acid change)** }\end{array}$} & \multirow[b]{2}{*}{$\begin{array}{l}\text { Minor allele } \\
\text { frequency } \\
()^{\&}\end{array}$} & \multicolumn{2}{|c|}{ MutPred analysis } & \multirow[b]{2}{*}{$\begin{array}{c}\text { Polymorphic background in the } \\
\text { Patients }{ }^{\#} \\
\text { or control alleles }\end{array}$} \\
\hline & & & & $\begin{array}{c}\text { Probability of } \\
\text { deleterious } \\
\text { mutation }\end{array}$ & $\begin{array}{c}\text { Confident } \\
\text { in-silico hypotheses }\end{array}$ & \\
\hline Ex.1 & rs11248061 & c. $24 C>A(A 8 A)$ & NA $(0.42)$ & . & & $\begin{array}{l}15,24,26,27,32,35,37,44,60,62,64 \\
68,69,70,72,73,75,76,79,80,81,82 \\
85,86,87,89,90,92,93,98,99,102\end{array}$ \\
\hline Ex.1 & rs10902762 & c. $60 \mathrm{G}>\mathrm{A}(\mathrm{A} 20 \mathrm{~A})$ & NA $(0.44)$ & . & & $\begin{array}{l}15,24,26,27,32,35,37,44,60,62,64 \\
68,69,70,72,73,75,76,80,82,85,86 \\
87,89,90,92,93,98,99,102\end{array}$ \\
\hline Ex.1 & rs10794537 & c.99T>G (Q33H) & NA (0.19) & 0.21 & None & $\begin{array}{l}17,20,21,23,25,30,33,39,40,41,43 \\
44,45,46,52,53,54,55,57,60,61,63 \\
64,65,76,79,91,96,100,101\end{array}$ \\
\hline Intr. 2 & & c. $299+6 \mathrm{C}>\mathrm{T}^{+}$ & $(0.04)$ & . & & control alleles \\
\hline Intr. 2 & & c. $299+7 G>A$ & $(0.01)$ & . & & control alleles \\
\hline Intr. 2 & & c. $299+9 \mathrm{C}>\mathrm{T}^{++}$ & $(0.00)$ & . & & 20 \\
\hline Intr. 2 & & c. $300-44 \mathrm{C}>\mathrm{T}^{+}$ & $(0.07)$ & . & & $37,83,72$ \\
\hline Ex.3 & rs3755955 & c.314G>A (R105Q) & $0.15(0.18)$ & 0.12 & None & $\begin{array}{l}24,28,29,35,45,51,53,59,60,67,71 \\
75\end{array}$ \\
\hline Ex.3 & rs3755954 & c.352C $>\mathrm{T}(\mathrm{L} 118 \mathrm{~L})$ & $0.16(0.14)$ & . & & $\begin{array}{l}17,20,21,23,25,27,30,33,34,35,39,4 \\
0,41,43,44,46,49,52,54,55,57,59,60 \\
61,62,63,64,65,70,71,76,79,83,84, \\
91,96,100,101\end{array}$ \\
\hline Ex.4 & & c. $408 \mathrm{C}>\mathrm{T}(\mathrm{A} 136 \mathrm{~A})$ & $(0.01)$ & . & & control alleles \\
\hline Ex.5 & rs6815946 & c.543T>C (N181N) & $0.14(0.18)$ & . & & $24,28,29,49,51,59,60,67,71$ \\
\hline Intr. 5 & & c.589+20d up G & $(0.00)$ & . & & 22 \\
\hline Intr. 5 & rs6829789 & c. $590-45 \mathrm{G}>\mathrm{C}$ & NA $(0.18)$ & . & & $24,28,29,51,53,59,60,67,71$ \\
\hline Intr. 5 & rs 6848974 & c. $590-8 \mathrm{C}>\mathrm{T}$ & NA $(0.18)$ & . & & $\begin{array}{l}19,24,28,29,45,49,51,53,59,60,67 \\
71\end{array}$ \\
\hline Intr. 6 & & c. $792+12 \mathrm{C}>\mathrm{T}$ & $(0.01)$ & . & & control alleles \\
\hline Intr. 6 & & c. $792+14 C>T$ & $(0.00)$ & . & & 17 \\
\hline Ex. 7 & rs11480689 & $c .891 \mathrm{C}>\mathrm{T}(\mathrm{N} 297 \mathrm{~N})$ & NA (0.04) & . & & $21,42,43,52$ \\
\hline Ex. 7 & rs 6830825 & c. $942 \mathrm{G}>\mathrm{C}(\mathrm{A} 314 \mathrm{~A})$ & NA (0.16) & . & & $19,24,28,49,51,59,60,67,71$ \\
\hline Intr. 7 & rs6811373 & c. $972+48 \mathrm{~A}>\mathrm{G}$ & $0.14(0.07)$ & . & & $28,29,49,51,53,67,71$ \\
\hline Intr. 7 & rs6831021 & c. $973-45 \mathrm{G}>\mathrm{C}$ & NA & . & & $28,29,49,51,53,67$ \\
\hline Ex. 8 & rs6831280 & c. $1081 \mathrm{G}>\mathrm{A}(\mathrm{A} 361 \mathrm{~T})$ & $0.21(0.17)$ & 0.13 & None & $28,49,53,59,60,67$ \\
\hline Ex. 8 & rs 6836258 & c. $1164 \mathrm{G}>\mathrm{C}(\mathrm{T} 388 \mathrm{~T})$ & $\mathrm{NA}(0.17)$ & . & & $28,49,53,59,60,67$ \\
\hline Ex. 8 & & c. $1174 \mathrm{C}>\mathrm{T}(\mathrm{L} 392 \mathrm{~L})^{+}$ & $(0.01)$ & . & & control alleles \\
\hline Intr. 8 & & c. $1190-10$ insC $^{+}$ & $(0.15)$ & . & & $19,24,28,29,45,49,51,53,67,71$ \\
\hline Ex. 9 & rs115790973 & c. $1230 \mathrm{C}>\mathrm{G}(\mathrm{T} 410 \mathrm{~T})$ & NA $(0.16)$ & . & & $\begin{array}{l}19,24,28,29,45,49,51,53 \\
59,60,67,71\end{array}$ \\
\hline Ex. 9 & & c. $1345 \mathrm{C}>\mathrm{A}(\mathrm{H} 449 \mathrm{~N})$ & $(0.00)$ & 0.40 & None & 46 \\
\hline Ex. 9 & rs73066479 & c.1360G >A (V454I) & NA (0.17) & 0.10 & None & $\begin{array}{l}19,24,28,29,45,49,51,53,59,60,67 \\
1\end{array}$ \\
\hline Intr.9 & & c. $1403+36 \mathrm{~T}>\mathrm{C}^{+}$ & $(0.17)$ & . & & $19,24,45,51,59,60,67,71$ \\
\hline Ex. 10 & rs115929690 & c. $1467 \mathrm{C}>\mathrm{T}(\mathrm{R} 489 \mathrm{R})$ & $\mathrm{NA}(0.14)$ & . & & $19,24,45,49,51,53,59,60,67,71$ \\
\hline Ex. 10 & & c. $1473 C>A(G 491 G)$ & $(0.01)$ & . & & control alleles \\
\hline Ex. 10 & & C.1515C>G (R505R) & $(0.00)$ & . & & 19 \\
\hline Intr. 10 & & c. $1524+41 G>T^{+}$ & $(0.11)$ & . & & $45,49,53,59,60,67,71$ \\
\hline Intr. 10 & rs113289555 & c. $1524+53 G>T$ & $\mathrm{NA}(0.29)$ & . & & $\begin{array}{l}18,19,22,24,26,29,31,32,36,37,39,4 \\
7,48,50,51,55,56,58,65,66,68,69,70 \\
, 74,75,76,77,81,82,85,86,88,90,92, \\
95,97,98,100,102\end{array}$ \\
\hline Intr. 10 & & c. $1525-38 \mathrm{~T}>\mathrm{C}^{+}$ & $(0.09)$ & . & & 28 \\
\hline Intr. 12 & rs2305488 & c. $1727+72 T>G$ & 0.11 & . & & $19,24,29,49,53,67$ \\
\hline Intr. 12 & rs2305489 & c. $1727+75 G>T$ & 0.04 & . & & $21,42,43,52$ \\
\hline Ex. 13 & & c.1771G $>\mathrm{A}(\mathrm{A} 591 \mathrm{~T})^{+++}$ & $(0.00)$ & 0.15 & None & $17,19,22,23,30,33$ \\
\hline
\end{tabular}

Legend: dbSNP, the Single Nucleotide Polymorphism database, is available at http://www.ncbi.nlm.nih.gov/projects/SNP/; *GenBank-EMBL accession no. NM_000203.3; ${ }^{* *}$ GenBank-EMBL accession no. NP_000194; the minor allele frequencies were ${ }^{\S}$ obtained from dbSNP or ( $)^{\&}$ calculated from 100 Caucasian control alleles (novel polymorphisms, in bold); NA: not available; \#patient number according to Table $1 .{ }^{+}$Scott et al., (1995); ${ }^{++}$Venturi et al., (2002); ${ }^{+++}$neutral change shown in vitro by Beesley et al.(2001); ${ }^{\bullet}$ Li et al., (2009) a nd Mort et al., (2010). 
2

3

4

5

6

Supp. Table S3. MutPred an alysis for IDUA missense mutations

\begin{tabular}{|c|c|c|c|}
\hline \multirow{2}{*}{ Mutation } & \multirow{2}{*}{$\begin{array}{l}\text { Probability of } \\
\text { deleterious } \\
\text { mutation }\end{array}$} & \multicolumn{2}{|c|}{ Molecular mechanism altered } \\
\hline & & Confident Hypotheses & Very Confident Hypotheses \\
\hline p.M1? & 0.99 & & \\
\hline p.G51D & 0.97 & $\begin{array}{c}\text { Gain of relative solvent accessibility }(P=0.0215) \\
\text { Gain of solvent a ccessibility }(P=0.0306)\end{array}$ & \\
\hline p.Y76C & 0.73 & & \\
\hline p.G84R & 0.93 & $\begin{array}{c}\text { Gain of MoRF binding }(P=0.0303) \\
\text { Gain of solvent a ccessibility }(P=0.0456)\end{array}$ & \\
\hline p.R89W & 0.96 & & \\
\hline p.T103P & 0.36 & \multicolumn{2}{|c|}{$\begin{array}{ll} & \text { See details in Supp. Table S4 } \\
\end{array}$} \\
\hline p.E178K & 0.97 & $\begin{array}{c}\text { Gain of MoRF binding }(P=0.0143) \\
\text { Gain of ubiquitination at } E 178(P=0.0258) \\
\text { Loss of catalytic residue at W180 }(P=0.0315)\end{array}$ & Gain of methylation at E178 $(P=0.0036)$ \\
\hline p.F188L* & 0.95 & & \\
\hline p.S423R* & 0.92 & Gain of methylation at S423 $(P=0.0279)$ & \\
\hline p.G219E & 0.89 & $\begin{array}{c}\text { Gain of solvent a ccessibility }(P=0.0145) \\
\text { Gain of relative solvent accessibility }(P=0.0215)\end{array}$ & \\
\hline p.G265R & 0.95 & $\begin{array}{c}\text { Gain of methylation at G265 }(P=0.0219) \\
\text { Loss of helix }(P=0.028) \\
\text { Gain of loop }(P=0.0312) \\
\text { Gain of MoRF binding }(P=0.033)\end{array}$ & \\
\hline p.E276K & 0.76 & $x_{2}^{2}$ & \\
\hline p.W306L & 0.82 & Loss of catalytic residue at P309 $(\mathrm{P}=0.0327)$ & \\
\hline p.A327P & 0.84 & $\begin{array}{c}\text { Gain of relative solvent accessibility }(P=0.0215) \\
\text { Gain of methylation at } K 324(P=0.0487)\end{array}$ & \\
\hline p.N348K & 0.85 & $\begin{array}{c}\text { Loss of sheet }(P=0.0181) \\
\text { Gain of ubiquitination at N348 }(P=0.0192) \\
\text { Gain of methylation at } N 348(P=0.0295) \\
\text { Loss of stability }(P=0.0381)\end{array}$ & \\
\hline p.P385R & 0.82 & $\begin{array}{r}\text { Gain of relative solvent accessibility }(P=0.0215) \\
\text { Loss of sheet }(P=0.0315) \\
\text { Loss of loop }(P=0.0374) \\
\text { Gain of helix }(P=0.0425)\end{array}$ & $\begin{array}{l}\text { Gain of solvent a ccessibility }(P=0.0055) \\
\text { Gain of MoRF binding }(P=0.0081)\end{array}$ \\
\hline p.L396P & 0.83 & $\begin{array}{l}\text { Loss of helix }(P=0.0167) \\
\text { Gain of loop }(P=0.0195)\end{array}$ & Loss of stability $(P=0.0047)$ \\
\hline p.A436P & 0.45 & See details in Supp & p. Table S4 \\
\hline p.L490P & 0.86 & $\begin{array}{l}\text { Gain of disorder }(P=0.0154) \\
\text { Loss of helix }(P=0.028) \\
\text { Loss of stability }(P=0.0441)\end{array}$ & \\
\hline p.R492P & 0.83 & & Loss of MoRF binding $(P=0.0011)$ \\
\hline p.P496R & 0.95 & & Gain of MoRF binding $(P=0.0078)$ \\
\hline p.P533R & 0.94 & & Gain of MoRF binding $(P=0.0068)$ \\
\hline p.L535F & 0.59 & & 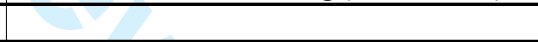 \\
\hline
\end{tabular}

*mutations in cis on the same allele; MoRFs=Molecular Recognition Features

Supp. Table S4. Bio informatic an alysis of novel missense variants of uncertain pathogenicity

\begin{tabular}{|c|c|c|c|c|c|c|}
\hline $\begin{array}{l}\text { Nucleotide } \\
\text { substitution }\end{array}$ & $\begin{array}{l}\text { Am in o a cid } \\
\text { change }\end{array}$ & $\begin{array}{c}\text { Conservation } \\
\text { base level } \\
\text { (phyloP) }\end{array}$ & $\begin{array}{l}\text { MutPred probability of } \\
\text { deleterious mutation }\end{array}$ & $\begin{array}{c}\text { SIFT } \\
\text { Prediction } \\
\text { (score) }\end{array}$ & $\begin{array}{l}\text { PolyPhen2 } \\
\text { (score) }\end{array}$ & $\begin{array}{l}\text { Splicing } \\
\text { disruption }\end{array}$ \\
\hline c. $307 \mathrm{~A}>\mathrm{C}$ & p.T103P & $\begin{array}{c}\text { Conserved } \\
(0.4)\end{array}$ & 0.36 & $\begin{array}{l}\text { Tolerated } \\
(0.5)\end{array}$ & $\begin{array}{l}\text { Benign } \\
(0.0)\end{array}$ & FALSE \\
\hline c. $1306 \mathrm{G}>\mathrm{C}$ & p.A436P & $\begin{array}{c}\text { Conserved } \\
(2.8)\end{array}$ & 0.45 & $\begin{array}{l}\text { Tole rated } \\
(0.2)\end{array}$ & $\begin{array}{l}\text { Possibly damaging } \\
(0.26)\end{array}$ & FALSE \\
\hline
\end{tabular}


20 Bertola et al.

2

Supp. Table S5. Prediction of consequences of $n$ ovel missense $m$ utations using the 3D homology model of the IDUA protein constructed by Rempel et al. [2005]

\begin{tabular}{|c|c|c|}
\hline MUTATION & PROTEIN POSITION & MODELLING ANALYSIS PREDICTION \\
\hline p.Y76C & Solvent accessible & $\begin{array}{l}\text { Large aromatic and polar side chain substituted by a smaller, highly reactive } \\
\text { one. }\end{array}$ \\
\hline p.G84R & Close to active site & Loss of $m$ ain chain flexibility and of solvent accessible surface. $G$ ain of charge. \\
\hline p.T103P & Solvent accessible & $\begin{array}{l}\text { Introduction of a new proline within a long loop (G101-N110) protruding into } \\
\text { the solvent. Acquisition of loop rigidity. Decrease in residue polarity. }\end{array}$ \\
\hline p.F188L* & Active site & $\begin{array}{l}\text { F188 belongs to an am ino acid cluster comprising aromatic residues (F143, } \\
\text { W180, W } 306, \text { Y } 343 \text { ) and residues bearing indole rings (H56, H91, H185). The } \\
\text { newly acquired } 188 \mathrm{~L} \text { residue would maintain the hydrophobicity but would } \\
\text { give rise to a loss of aromaticity. F188 is considered to be an active site } \\
\text { residue }\end{array}$ \\
\hline p.S423R* & Core & $\begin{array}{l}\text { Increase in size, alteration in charge. Disruption of local protein fold due to } \\
\text { steric hindrance }\end{array}$ \\
\hline p.G 219E & Core & $\begin{array}{l}\text { Increase in size, alteration in charge. Destabilisation of the local protein fold } \\
\text { due to steric hindrance }\end{array}$ \\
\hline p.E276K & Solvent accessible & $\begin{array}{l}\text { Alteration in charge (negative to positive). Change of the protein surface } \\
\text { electrostatic potential }\end{array}$ \\
\hline p.W306L & Core & $\begin{array}{l}\text { W306 belongs to an amino acid cluster comprising aromatic residues (F143, } \\
\text { W180, W } 306, \mathrm{Y} 343 \text { ) and residues bearing indole rings (H56, H91, H185). The } \\
\text { newly acquired } 306 \mathrm{~L} \text { residue would maintain the hydrophobicity but would } \\
\text { give rise to a loss of aromaticity. }\end{array}$ \\
\hline p.N348K & Solvent accessible & Alteration in surface local charge. \\
\hline p.P385R & Core & Loss of local rigidity. Destabilisation of the local protein fold. \\
\hline p.L396P & Solvent accessible & $\begin{array}{l}\text { Loss of long and branched hydrophobic side chain (leucine). Loss of local } \\
\text { flexibility in the edge of a turn. Loss oflocal protein fold. }\end{array}$ \\
\hline p.A436P & Solvent accessible & $\begin{array}{l}\text { Gain of } \mathrm{m} \text { ain chain rigidity (436P) which would disrupt the super-secondary } \\
\text { structure of the protein owing to its inability to form the main chain } \mathrm{H} \text {-bonds } \\
\text { that are required for } \beta \text {-sheet formation. }\end{array}$ \\
\hline
\end{tabular}

* mutations occur in cis on the same allele 
Supp. Figure S2. Graphical representation of the 12 IDUA splicing mutations identified in MPS I patients in the present study. A) Canonical consensus sequence of acceptor and donor splice sites (adapted from Cartegni et al, 2002); B) Positions of the IDUA splicing mutations in relation to the acceptor and donor splice sites. Note that only the involved sequences are reported. Affected nucleotides are given in red. The mutations are reported in square brackets. 
22 Bertola et al.

Supp Table S6. Genotype-phenotype correlation: comparison with existing data from the literature

\begin{tabular}{|c|c|c|c|c|}
\hline \multirow{2}{*}{\multicolumn{2}{|c|}{ GENOTYPES* }} & \multicolumn{2}{|c|}{$\begin{array}{l}\text { NO. OF PATIENTS } \\
\text { ANALYZED AND } \\
\text { (PHENOTYPE) }\end{array}$} & \multirow[t]{2}{*}{ REFERENCES } \\
\hline & & $\begin{array}{l}\text { THIS } \\
\text { STUDY }\end{array}$ & $\begin{array}{l}\text { OTHER } \\
\text { STUDIES }\end{array}$ & \\
\hline \multirow{9}{*}{ 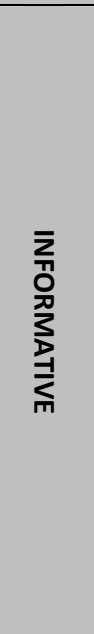 } & {$[p . W 402 X]+[p . W 402 X]$} & $12(H)$ & $46(H)$ & $\begin{array}{l}\text { Bunge et al. (1994); Gort et al. (1998); Hein et al. (2003); Li et al, } \\
\text { (2002); Matte et al. (2003); Scott et al. (1992); Vazna et al. (2009) }\end{array}$ \\
\hline & {$[p . Q 70 X]+[p . Q 70 X]$} & $9(\mathrm{H})$ & $26(H)$ & $\begin{array}{l}\text { Bunge et al. (1994); Gort et al. (1998); Hein et al. (2003); Scott et } \\
\text { al. (1992); Vazna et al. (2009); Venturi et al. (2002); Voskoboeva et } \\
\text { al. (1998) }\end{array}$ \\
\hline & {$[p . W 402 X]+[p . Q 70 X]$} & $4(\mathrm{H})$ & $19(H)$ & Bunge et al. (1994); Li et al. (2002); Scott et al. (1992) \\
\hline & {$[p . W 402 X]+[c .1650+5 G>A]$} & $1(H)$ & $2(\mathrm{H})$ & Vazna et al. (2009); Venturi et al. (2002); \\
\hline & {$[p . W 402 X]+[p . A 327 P]$} & $1(\mathrm{H})$ & $2(\mathrm{H})$ & Bunge et al. (1994); Vazna et al. (2009) \\
\hline & {$[p . A 327 P]+[p . A 327 P]$} & $1(H)$ & $1(\mathrm{H}-\mathrm{H} / \mathrm{S})$ & Gatti et al. (1997) \\
\hline & {$[p . G 51 D]+[p . G 51 D]$} & $2(\mathrm{H})$ & $1(H)$ & Gatti et al. (1997) \\
\hline & [p.Q70X]+[c.1333_1335del3] & $1(\mathrm{~S})$ & $1(\mathrm{~S})$ & Bunge et al. (1994) \\
\hline & {$[p . L 490 P)+[p . L 490 P]$} & $1(S)$ & $3(\mathrm{H} / \mathrm{S})$ & Beesley et al. (2001); Tieu et al. (1995) \\
\hline \multirow{4}{*}{ 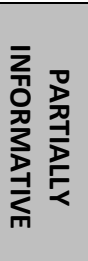 } & {$[p . P 533 R]+[p . P 533 R]$} & $2(H / S)$ & $8(\S)$ & $\begin{array}{l}\text { Alif et al. (1999); Gatti et al. (1997); Laradi et al. (2005); Matte et } \\
\text { al. (2003); Scott et al. (1992) }\end{array}$ \\
\hline & [p.P533R]+[p.P533R] & $1(\mathrm{H})$ & $11(\S)$ & Alif et al. (1999); Hein et al. (2003) \\
\hline & {$[p . G 51 D]+[p . P 533 R]$} & $1(H / S)$ & $2(\S)$ & Gatti et al. (1997); Venturi et al. (2002) \\
\hline & [c.46_57del12]+[c.46_57del12] & $2(\mathrm{H} / \mathrm{S})$ & $2(\mathrm{H})$ & Bunge et al. (1994); Venturi et al. (2002) \\
\hline
\end{tabular}

Legend: $\mathrm{H}=$ Hurler; $\mathrm{S}=\mathrm{Scheie}$; Note that only the comparable genotypes with existing data are reported in this table. For the other genotypes, refer to Table 1; § various phenotypes 